\title{
LOS DERECHOS DE LA NATURALEZA EN \\ EUROPA: HACIA NUEVOS PLANTEAMIENTOS \\ TRANSFORMADORES DE LA PROTECCIÓN AMBIENTAL
}

\author{
SUSANA BORRÀS PENTINAT ${ }^{1}$ \\ Universidad Rovira i Virgili \\ susana.borras@urv.cat
}

\author{
Cómo citar/Citation \\ Borràs Pentinat, S. (2020). \\ Los derechos de la naturaleza en Europa: hacia nuevos planteamientos \\ transformadores de la protección ambiental. \\ Revista de Derecho Comunitario Europeo, 65, 79-120. \\ doi: https://doi.org/10.18042/cepc/rdce.65.03
}

\section{Resumen}

En la actualidad, la Unión Europea posee una de las regulaciones jurídicas más estrictas en materia de protección ambiental, entre las que destacan las directivas de aves y hábitats, que constituyen la base de la Red Natura 2000, la mayor red coordinada de zonas protegidas que existe en el mundo. No obstante, los problemas ambientales persisten, tales como la contaminación difusa del agua, la baja calidad del aire en las zonas urbanas, el tratamiento insatisfactorio de los residuos y el declive de especies y hábitats.

En este contexto se plantea la necesidad y la posibilidad de promover una transición hacia un cambio de paradigma: del derecho a la Naturaleza a los derechos de la Naturaleza. Este replanteamiento de paradigma ya se está experimentando en muchos países: desde Ecuador o Bolivia, como primeros impulsores del biocentrismo, a Colombia, Nueva Zelanda, la India, entre muchos otros países.

Considerando este progresivo reconocimiento de los derechos de la Naturaleza en diferentes ordenamientos jurídicos, en este artículo se analiza, por una parte, las posibili-

1 Profesora agregada de Derecho Internacional Público y Relaciones Internacionales de la Universidad Rovira i Virgili de Tarragona. Este trabajo forma parte de una investigación más amplia realizada en el marco de las actividades de la Cátedra Jean Monnet sobre Derecho Ambiental de la UE (587220-EPP-1-2017-1-ES-EPPJMO-CHAIR) financiado por la Comisión Europea. 
dades jurídicas para favorecer esta transición biocéntrica en el seno de la Unión Europea, así como por otra también se apuntan los principales obstáculos existentes y el papel de los movimientos sociales para acelerar este proceso y solucionar la crisis ambiental.

\section{Palabras clave}

Naturaleza; política ambiental de la UE; biocentrismo; derechos de la Naturaleza; Red Natura 2000; acceso a la justicia en temas ambientales.

\section{THE RIGHTS OF NATURE IN EUROPE: TOWARDS NEW TRANSFORMATIVE APPROACHES OF THE ENVIRONMENTAL PROTECTION}

\section{Abstract}

At present, the European Union has one of the strictest environmental regulations in the world, such as the Birds and Habitats Directives, which constitute the basis of the Natura 2000, the largest coordinated network of protected areas in the world. However, environmental problems persist, such as diffuse water pollution, poor air quality in urban areas, unsatisfactory treatment of waste, and the decline of species and habitats.

In this context, the need and the possibility of promoting a transition towards a paradigm shift are raised: from the right to Nature to the rights of Nature. This paradigm rethinking is already being experienced in many parts of the world: from Ecuador or Bolivia, as the first drivers of biocentrism, to Colombia, New Zealand, India, among many other countries.

Considering the progressive recognition of the rights of Nature in many parts of the world, this article analyzes the legal possibilities to favor this biocentric transition in the European Union, as well as the main existing obstacles and the role of social movements to accelerate this process and solve the environmental crisis.

\section{Keywords}

Nature; EU environmental policy; Biocentrism; Nature’s rights; Natura 2000 Network; Access to justice in environmental matters.

\section{LES DROITS DE LA NATURE EN EUROPE: VERS DE NOUVELLES APPROCHES TRANSFORMATRICES DE LA PROTECTION DE L'ENVIRONNEMENT}

\section{Résumé}

À l'heure actuelle, l'Union européenne applique l'une des réglementations légales les plus strictes en matière de protection de l'environnement, notamment les 
directives «Oiseaux» et «Habitats», qui constituent la base du réseau Natura 2000, le plus grand réseau coordonné d'aires protégées. Il existe dans le monde. Cependant, des problèmes environnementaux persistent, tels que la pollution de l'eau diffuse, la mauvaise qualité de l'air en milieu urbain, le traitement insatisfaisant des déchets et le déclin des espèces et des habitats.

Dans ce contexte, la nécessité et la possibilité de promouvoir une transition vers un changement de paradigme sont évoquées: du droit à la nature aux droits de la nature. Ce paradigme de repenser est déjà expérimenté dans de nombreux pays: de l'Équateur ou de la Bolivie, premiers moteurs du biocentrisme, à la Colombie, à la Nouvelle-Zélande, à l'Inde, parmi beaucoup d'autres.

Considérant cette reconnaissance progressive des droits de la Nature dans différents systèmes juridiques, cet article analyse, d'une part, les possibilités juridiques de favoriser cette transition biocentrique au sein de l'Union européenne, ainsi que, d'autre part, les points principaux obstacles existants et rôle des mouvements sociaux pour accélérer ce processus et résoudre la crise environnementale.

\section{Mots clés}

La nature; Politique environnementale de l'UE; biocentrisme; Les droits de la nature; Réseau Natura 2000; l'accès à la justice en matière d'environnement. 
I. INTRODUCCIÓN: EL DESGASTE GENERALIZADO DE LA NATURALEZA. II. TENDENCIAS GLOBALES EN EL PROGRESIVO RECONOCIMIENTO DE LOS DERECHOS DE LA NATURALEZA. III. LA SITUACIÓN DE LA NATURALEZA EN LA UNIÓN EUROPEA. IV. LA CONSERVACIÓN DE LA NATURALEZA EN LA UE: DEL DERECHO A LA NATURALEZA A LOS DERECHOS DE LA NATURALEZA: 1. Factores tendenciales del actual marco de protección jurídica de la Naturaleza en la UE. 2. Opciones en el reconocimiento de los derechos de la Naturaleza en la UE: 2.1. Reconceptualización de la protección de la Naturaleza: como objeto a sujeto de protección. 2.2. Las opciones procesales de protección de los derechos ambientales. 2.3. La custodia de protección de la Naturaleza. V. AVANCES EN LA JURISPRUDENCIA DEL TJUE. VI. DEL RECONOCIMIENTO DE LOS DERECHOS DE LA CIUDADANÍA EUROPEA AL RECONOCIMIENTO DE LOS DERECHOS DE LA NATURALEZA: EL CONVENIO DE AARHUS Y LA INICIATIVA CIUDADANA EUROPEA: 1. Incrementar la democracia ambiental para proteger la Naturaleza. 2. El movimiento europeo por los derechos de la Naturaleza en la UE. VII. CONCLUSIONES. Biblografía.

\section{INTRODUCCIÓN: EL DESGASTE GENERALIZADO DE LA NATURALEZA}

A lo largo de la historia de la humanidad, la Tierra ha sido vista como un suministro infinito de recursos naturales para ser explotados libremente con fines de lucro, sin que la regulación jurídica nacional e internacional haya podido prevenir $\mathrm{o}$, al menos, frenar esta vorágine.

La relación de los países europeos con los recursos naturales no ha sido, precisamente, armónica. Si se remonta históricamente, la conquista europea de los pueblos indígenas en África, América del Norte y del Sur y el casi exterminio de sus culturas y hábitats son un buen ejemplo. Así, la historia latinoamericana, en particular, ha sido moldeada por siglos de saqueo extranjero de sus recursos naturales, comenzando en el siglo Xvi con la ambición del Imperio español por la plata y el oro (Pagden, 2015: 243). Más recientemente, las principales beneficiarias han sido las corporaciones multinacionales, muchas de las cuales también se nutren de las brutales dictaduras militares, respaldadas por los Estados Unidos en la década de los sesenta y ochenta. La 
actualidad no ofrece un mejor panorama: la estrangulación de las economías y sociedades del continente americano y africano ${ }^{2}$ por parte de intereses europeos perdura con la complacencia de actividades empresariales altamente impactantes para el medio ambiente y las poblaciones locales.

En este contexto, la perspectiva del biocentrismo jurídico, mediante el reconocimiento de los derechos de la Naturaleza (Boff, 2008), constituye una contestación de cómo esta idea europea del dominio humano del planeta se impuso en las Américas y en África. En contraste, las nuevas formas de resistencia están inspiradas y vinculadas a las culturas indígenas, que se ven a sí mismas como parte de un continuo ecológico (Martínez y Acosta, 2017: 2932).

En este orden de ideas, es necesario plantearse dos cuestiones fundamentales. En primer lugar, si esta misma contestación puede servir para proporcionar una respuesta frente a la misma crisis ambiental, existente en todo el mundo y en la misma Unión Europea (UE), fruto del resultado de un paradigma que considera a la Naturaleza como una propiedad, una mercancía y generadora de servicios, legitimando su explotación para obtener ganancias económicas y, al mismo tiempo, impidiendo la participación directa de los ciudadanos y ciudadanas en su protección. Al otorgar a los ecosistemas y las especies el derecho a existir, persistir y renovar sus ciclos naturales, une y capacita a los ciudadanos europeos comunes para defender la naturaleza utilizando las normas jurídicas, iniciando una nueva era de gobernanza ecológica comunitaria, dando el ejemplo a otros países. Y, en segundo lugar, si el posible reconocimiento de los derechos de la Naturaleza en la UE constituye un continuum acaparamiento de los saberes indígenas por parte de los históricos colonizadores europeos. Al respecto, pensando en el beneficio de la unidad ecológica que constituye la Naturaleza de por sí, la extensión de la visión cosmológica indígena a otros territorios es sin duda necesaria y beneficiosa, incluso para revertir prácticas empresariales indeseables fuera de la UE.

Los indicadores actuales, centrados en el crecimiento económico, no revelan lo sostenible que es realmente el desarrollo socioeconómico de la UE (Connelly, 2012: 199). Incorporar el valor del capital natural en la toma de decisiones económicas es una forma de mejorar esto, pero no previene una

2 Consúltese Honest Accounts 2017: How the world profits from Africa's wealth (Cuentas honestas 2017: Cómo el mundo se beneficia de la riqueza de Africa). Véase también, por ejemplo, la Resolución del Parlamento Europeo sobre la explotación ilegal de los recursos naturales en la República Democrática del Congo, de 5 de julio de 2001. Disponible en: http://www.europarl.europa.eu/sides/getDoc.do?pubRef=-//EP//TEXT+TA+P5-TA-2001-0409+0+DOC+XML+V0//ES (consulta el 1 de marzo de 2019). 
mercantilización de la Naturaleza (Bozonnet, 2014: 89-104). Sí, en cambio, los enfoques como los derechos de la Naturaleza que deben formar parte, necesariamente, del debate.

Si bien han pasado varias décadas desde la adopción de las primeras normas y políticas medioambientales de la UE, la situación y los indicadores medioambientales no parecen haber mejorado. Según los informes de la Agencia Europea de Medio Ambiente ${ }^{3}$, la destrucción ambiental en la UE continúa y el cambio climático está ocurriendo. Los impactos son y serán devastadores, no solo para los ecosistemas, sino para los humanos también, menguando su bienestar. Bajo esas circunstancias, no hay un mejor momento para que la UE siga los desarrollos internacionales y se plantee un cambio de paradigma, mediante la introducción de nuevos marcos jurídicos, que reconozcan a la Naturaleza el derecho a existir, persistir, mantener y regenerar sus ciclos vitales e integrales.

El interés por plantear el reconocimiento de un biocentrismo jurídico y de los derechos de la Naturaleza en el ámbito de la UE se centra en dos razones principales. Una, porque las políticas de la UE tienen un impacto muy importante sobre la Naturaleza (İzci, 2005: 101-114); pero, por otra parte, el marco regulador de protección ambiental impulsado desde la misma UE es suficientemente significativo, especialmente, mediante las denominadas «Directivas de la Naturaleza», como para promover esta transición. La Directiva de la Unión Europea relativa a la Conservación de los Hábitats Naturales y de la Fauna y Flora silvestre ${ }^{4}$, la conocida como Directiva Hábitat, así como la Directiva relativa a la conservación de las aves silvestres ${ }^{5}$, constituyen los ejemplos más significativos de una normativa legal, que sigue esta filosofía biocéntrica de protección de la naturaleza (Schoukens, 2018: 309).

3 European Environment Agency (2016), Key findings - Climate change, impacts and vulnerability in Europe 2016. Disponible en: https:/www.eea.europa.eu/publications/climate-change-impacts-and-vulnerability-2016/key-findings (consulta el 1 de marzo de 2019).

4 Directiva 92/43/CEE del Consejo, de 21 de mayo de 1992, relativa a la conservación de los hábitats naturales y de la fauna y flora silvestres (DO L 206 de 22.7.1992, pp. 7-50). Las modificaciones sucesivas de la Directiva 92/43/CEE se han incorporado al texto original. Esta versión consolidada disponible en: https://eur-lex.europa.eu/ legal-content/ES/TXT/?uri=celex:01992L0043-20130701 (consulta el 1 de marzo de 2019).

5 Directiva 2009/147/CE del Parlamento Europeo y del Consejo, de 30 de noviembre de 2009, relativa a la conservación de las aves silvestres (DO L 20 de 26.1.2010, pp. 7-25). 
Sobre la base de estas reflexiones previas, el presente artículo analiza, en primer lugar, el progresivo reconocimiento de los derechos de la Naturaleza en muchas partes del mundo, aportando una evidencia de la existencia de una tendencia remarcable, lo suficientemente influyente sobre la sociedad civil europea y la misma UE. A continuación, en segundo lugar, se procede a analizar la situación de la protección jurídica de la Naturaleza, mediante las denominadas "Directivas de la Naturaleza» y la posibilidad de su extensión hacia el reconocimiento biocéntrico de protección en la Unión Europea.

Y finalmente, en tercer lugar, se aborda cómo el reconocimiento y el ejercicio de derechos reconocidos a la ciudadanía europea pueden abrir potenciales espacios más democráticos y próximos de la UE a sus pueblos, permitiendo articular vías procesales como los derechos ambientales del Convenio de Aarhus ${ }^{6}$, algunos de ellos paralizados a nivel de la UE, como es el acceso a la justicia en la UE. No obstante, tal y como se analiza en este estudio, el reconocimiento y la atribución de derechos de la Naturaleza en la UE surgen por el reclamo y la movilización de base de la sociedad civil organizada, constituyendo un posible reflejo de una nueva tendencia bottom-up (de abajo arriba). En este orden de ideas, surge el planteamiento de quién debe garantizar la protección y efectividad de estos derechos, en caso de un posible reconocimiento de derechos a favor de la Naturaleza.

La reflexión de estas cuestiones permite finalmente plantear las posibilidades reales, así como las dificultades potenciales, de reconocer a la Naturaleza y sus derechos, en el contexto de la integración europea.

\section{TENDENCIAS GLOBALES EN EL PROGRESIVO RECONOCIMIENTO DE LOS DERECHOS DE LA NATURALEZA}

En la actualidad, ya son muchos los países que están avanzando hacia el reconocimiento del derecho humano a un medio ambiente limpio y saludable. No obstante, otros tantos han dado un paso más allá y han otorgado derechos a la Naturaleza, iniciando un giro en la protección del medio ambiente, del antropocentrismo al biocentrismo (Gudynas, 2010: 51).

6 Decisión 2005/370/CE del Consejo, de 17 de febrero de 2005, sobre la celebración, en nombre de la Comunidad Europea, del Convenio sobre el acceso a la información, la participación del público en la toma de decisiones y el acceso a la justicia en materia de medio ambiente (DO L 124 de 17.5.2005, pp. 1-3). Convenio sobre el acceso a la información, la participación del público en la toma de decisiones y el acceso a la justicia en materia de medio ambiente (DO L 124 de 17.5.2005, pp. 4-20). 
El proceso de atribución de derechos a la Naturaleza se ha producido concibiendo los "Derechos de la Naturaleza» como: «Los derechos de las especies no humanas, elementos del entorno natural y [...] objetos inanimados para una existencia continua no amenazada por las actividades humanas" (Boyd, 2017: 137). Aun más allá, tal y como recuerdan Acosta y Martínez (2017), ya en la Constitución ecuatoriana de 2008, en el capítulo séptimo, art. 71, se señala que: «(l)a naturaleza o Pacha Mama» es "donde se reproduce y realiza la vida» $\mathrm{y}$ «tiene derecho a que se respete integralmente su existencia y el mantenimiento y regeneración de sus ciclos vitales, estructura, funciones y procesos evolutivos». Además, se considera que «(t)oda persona, comunidad, pueblo o nacionalidad podrá exigir a la autoridad pública el cumplimiento de los derechos de la naturaleza»y, en el art. 72 , se contempla que la Naturaleza tiene derecho a la restauración (Martínez y Acosta, 2017: 2932).

En este sentido, el reconocimiento y la juridificación de los derechos de la Naturaleza garantiza que los seres humanos puedan vivir en un entorno sano y limpio, tener derecho al disfrute de la vida y reconocer los derechos de nuestro medio ambiente, así como otorgar a la naturaleza sus propios derechos, similares a la perspectiva indígena (Borrás, 2016: 113-143).

Así, las tendencias en el reconocimiento de la atribución de derechos a la Naturaleza se han producido, en muchos países, principalmente, por una parte, por la particular relación o vínculo de una determinada población con su entorno, por diversos motivos basados en la sacralidad, la espiritualidad y el valor intrínsecamente excepcional de los recursos naturales; o, por otra, por la relación de dependencia de una determinada población respecto a la Naturaleza con la finalidad de garantizar su subsistencia.

Si bien en contextos en los que la población tiene un vínculo espiritual, basado en la concepción cosmológica de la Naturaleza y su relación con ella, la atribución de derechos responde a un carácter estrictamente biocéntrico. En cambio, la protección de la Naturaleza por su valor excepcional y de dependencia tiene un significado más discutible de reconocimiento de los derechos de la Naturaleza, de corte antropocentrista de la protección e incluso utilitarista. En todo caso, estos diferentes factores han coincidido en un mismo punto: en el reconocimiento y atribución de derechos a favor de la Naturaleza.

Esto permite, sin duda, salvar un obstáculo inicial en la concepción de los derechos de la Naturaleza en la Unión Europea. Así, entre las legislaciones protectoras de la Naturaleza, la más antigua a nivel constitucional se sitúa en el contexto europeo: la Constitución de Weimar de 1919, que, si bien tiene fama de ser una de las constituciones pioneras en incorporar los derechos sociales juntamente con la Constitución de Querétaro de 1917, la de Weimar es la primera que protege a la Naturaleza. La Constitución de Weimar establecía, 
en su art. 150, que «la Naturaleza goza de la protección y auxilios del Estado» (Zweers, 2000: 54).

A pesar de este antecedente remoto, pero significativo, es importante apuntar que los mayores reconocimientos normativos de los derechos de la Naturaleza se produjeron en el conteniente americano. En concreto, los primeros reconocimientos se producen a partir de 2006, cuando diferentes municipios locales en los Estados Unidos, como el municipio de Tamaqua, el condado de Schuylkill, en Pensilvania ${ }^{7}$, adoptaron diferentes ordenanzas, incluyendo los derechos de la Naturaleza. Desde entonces, más de dos docenas de comunidades en los Estados Unidos ya han adoptado leyes locales que reconocen los derechos de la Naturaleza.

En 2008, Ecuador se convirtió en el primer país en proteger, jurídicamente, la Pachamama o Madre Naturaleza, al incluir los derechos de la Naturaleza en su Constitución, aprobada mediante referéndum, realizado el 28 de septiembre de 2008 (Macías Gómez, 2010: 151; Martínez y Acosta, 2014: 120). Este reconocimiento constituye la culminación, en materia ambiental, de un proceso de constitucionalización del medio ambiente que se ha venido desarrollando en los países latinoamericanos (Daly, 2012: 63; Gudynas, 2009: 87; Acosta y Martínez, 2009).

Dos años después, en 2010, Bolivia aprobó la Ley 071 de Derechos de la Madre Tierra ${ }^{8}$, creando once derechos específicos del medio ambiente. Esto se precipitó cuando 30.000 personas de más de cien países se reunieron en abril de 2010 en Cochabamba, Bolivia, para crear un documento llamado «La Declaración Universal de los Derechos de la Madre Tierra» (Carwil Bjork, 2012).

Los avances no solo se han producido a nivel de reconocimiento jurídico, sino también a nivel jurisprudencial, especialmente en el reconocimiento de derechos de determinados recursos, como bosques y ríos (O’Donnell y Talbot-Jones, 2018: 7). Uno de los primeros casos en los que se planteó la cuestión de los derechos de la Naturaleza fue a partir del caso del bosque californiano de los Sequoyas, en 1972, en donde el desmedido afán de lucro corporativo pretendía convertir el hábitat de los enormes y milenarios árboles en un parque de diversiones, generando una batalla legal en la que jueces y

7 Véase Tamaqua Borough, Schuylkill County, Pennsylvania Ordinance 612 of 2006. Disponible en: https://www.worldcat.org/title/code-of-ordinances-of-the-borough-of-tamaqua/oclc/11006698 (consulta el 1 de marzo de 2019).

8 Ley 071 de 21 de diciembre de 2010, sobre la Ley de derechos de la Madre Tierra. Gaceta Oficial del Estado Plurinacional de Bolivia. Disponible en: http://gacetaoficialdebolivia.gob.bo/index.php/normas/view/138877 (consulta el 1 de marzo de 2019). 
pensadores se preguntaron si los árboles debían tener derecho a comparecer en juicio9. Esta misma reflexión llevó a varios autores de alrededor del mundo a abordar esta cuestión. Solo para mencionar algunos: Christopher Stone (1972) en Estados Unidos, Godofredo Stutzin (1984) en Chile o Cormac Cullinan (2002) en Sudáfrica.

En este sentido, la práctica jurisprudencial ha abarcado no solo la protección de la naturaleza en sí, sino también la protección de bienes inmateriales y espirituales, que garantizan su preservación, como la protección de sitios sagrados o de los conocimientos ancestrales (Shelton, 2015). Un buen ejemplo, en el caso de Ecuador, fue la decisión judicial emitida el 30 de marzo de 2011 por la Audiencia Provincial de Loja, que concedió un requerimiento judicial contra el Gobierno Provincial de Loja a dejar de violar los derechos constitucionales del río Vilcabama de existir y mantener sus ciclos vitales, estructura, funciones y procesos evolutivos, amenazados por los trabajos de excavación finalizados por la construcción de una nueva carretera provincial. Este fue el primer caso de éxito de los derechos de la Naturaleza en virtud del art. 71 de la Constitución ecuatoriana. La Acción de Protección, resuelta en segunda instancia por la Sala Penal de la Corte Provincial de Loja ${ }^{10}$, fue presentada por Richard Frederick Wheeler y Eleanos Geer Huddle en contra del Gobierno Provincial de Loja «a favor de la Naturaleza particularmente a favor del río Vilcabamba" por los trabajos de ampliación de la carretera Vilcabamba-Quinara. La Sala concedió el recurso, aceptando que «la acción de protección resulta la única vía idónea y eficaz para poner fin y remediar de manera inmediata un daño ambiental focalizado" y aplicando el principio de precaución, dicen los jueces, "[...] hasta tanto se demuestre objetivamente que no existe la probabilidad o el peligro cierto de que las tareas que se realicen en una determinada zona produzcan contaminación o conlleven daño ambiental, es deber de los Jueces constitucionales propender de inmediato al resguardo y hacer efectiva la tutela judicial de los derechos de la Naturaleza, efectuando lo que fuera necesario para evitar que sea contaminada, o remediar. Nótese que consideramos incluso que en relación al medio ambiente no se trabaja solo con la certeza de daño sino que se apunta a la

9 United States Supreme Court. Sierra Club v. Morton. 405 U.S. 727 (1972). Decided April 19, 1972.

10 Sentencia Causa de 30 de marzo del 2011, Acción de Protección 11121-2011-00010, Sala Penal de la Corte Provincial de Loja. Wheeler versus Director de la Procuraduría General Del Estado en Loja, Juicio, http://therightsofnature.org/first-ron-case-ecuador/ (consulta el 23 de octubre de 2019). 
probabilidad $[\ldots] »^{11}$. La Sala recordó asimismo que la Constitución «[...] sin precedente en la historia de la humanidad, reconoce a la naturaleza como sujeto de derechos [...]»; asume como un hecho evidente e indiscutible la «importancia de la Naturaleza», a tal punto que considera "que cualquier argumento respecto a ello resulta sucinto y redundante», incorporando en la decisión la idea de que los daños causados a ella son «daños generacionales», que define como «aquellos que por su magnitud repercuten no solo en la generación actual sino que sus efectos van a impactar en las generaciones futuras $[\ldots]_{»}{ }^{12}$.

En 2017, el Tribunal superior del estado indio de Uttarajand dictaminó que el Ganges y su principal afluente, el Yamuna, ambos considerados sagrados por millones de hindúes, tienen derecho de estar legalmente protegidos y no ser dañados, y pueden ser parte en disputas, reconociendo así su personalidad jurídica ${ }^{13}$. La Corte ordenó que los dos ríos sean representados por el director de la Misión Nacional para el Ganges Limpio, un órgano gubernamental que supervisa proyectos y la conservación del río, así como el secretario jefe del estado y el abogado general. Si bien esta decisión fue anulada posteriormente por la Corte Suprema, esta declaró como seres vivos a los glaciares Gangotri y Yamunotri ${ }^{14}$. Esta decisión se tomó con el fin de protegerlos de la creciente contaminación causada tanto por los locales como por los miles de visitantes que llegan a esta región del Himalaya.

En Nueva Zelanda también se declaró al río Whanganui como una entidad viviente y se designó a dos guardianes para proteger sus intereses. Si bien Nueva Zelanda aún no ha adoptado formalmente los derechos de la Naturaleza en alguna ley estatutaria o constitucional, la nación ya había reconocido los derechos inherentes de la Naturaleza mediante la concesión de personalidad jurídica a tierras y ríos (Davison, 2017; Roy, 2017). Así, en 2013, el Parque Nacional Te Urewera fue reconocido como persona jurídica.

Otro caso de interés es el de la Sala Sexta de Revisión de la Corte Constitucional de Colombia, que declaró, mediante su sentencia, que la cuenca del río Atrato posee derechos de protección, conservación, mantenimiento y restauración ${ }^{15}$. En esta decisión, la Corte amparó los derechos fundamentales a

11 Ibid., considerando quinto.

12 Ibid., considerandos séptimo y octavo.

13 Vidya Varuthi Thirthia Swamigal v. Baluswami Ayyar, [1922] AIR. [online] URL: https://indiankanoon.org/doc/242776/ (consulta el 10 de octubre de 2018).

14 Mohd. Salim v. State of Uttarakhand \& others, March 20, 2017. URL: https://indiankanoon.org/doc/89903027/ (consulta el 24 de octubre de 2019).

15 Esta fue una acción de tutela interpuesta por el Centro de Estudios para la Justicia Social «Tierra Digna», en representación del Consejo Comunitario Mayor de la Orga- 
la vida, a la salud, al agua, a la seguridad alimentaria, al medio ambiente sano, a la cultura y al territorio de las comunidades étnicas (negras e indígenas) que habitan la cuenca del río Atrato y sus afluentes, que vienen siendo víctimas de la explotación minera ilegal en el departamento de Chocó. La misma Corte Suprema de Justicia de Colombia emitió una sentencia, el 5 de abril de 2018, en la que se declara que la Amazonia, como región ecológica, es un sujeto de derechos. En concreto, se refiere a que la Amazonia es un «ecosistema vital para el devenir global», y que, en aras de protegerla, se la reconoce «como entidad "sujeto de derechos", titular de la protección, de la conservación, mantenimiento y restauración a cargo del Estado y las entidades regionales que la integran» ${ }^{16}$.

En otros países, el reconocimiento de esta tendencia biocéntrica no se ha producido desde la atribución de derechos a la Naturaleza, sino de obligaciones de protección de la Naturaleza. En efecto, países como Suiza, Portugal, Francia, Colombia y Brasil han especificado un conjunto de obligaciones con el gobierno en relación con la Naturaleza y su protección (Boyd, 2011: 227). Por ejemplo, la Constitución de la República Portuguesa (7a revisión, 25 de abril de 1976) establece los deberes del gobierno, en concreto el art. 66 (2) afirma que para garantizar el disfrute del derecho al medio ambiente en un marco general de desarrollo sostenible, actuando a través de los organismos apropiados y con la participación y participación de los ciudadanos, el Estado debe encargarse de: a) Prevenir y controlar la contaminación y sus efectos y las formas dañinas de erosión. b) Llevar a cabo y promover la planificación urbana y rural con miras a la ubicación correcta de las actividades, el desarrollo económico y social equilibrado y la mejora del paisaje. c) Crear y desarrollar reservas y parques naturales y recreativos, y clasificar y proteger paisajes y lugares, de manera que se garantice la conservación de la Naturaleza y la preservación de los valores y bienes culturales de interés histórico o

nización Popular Campesina del Alto Atrato (Cocomopoca), el Consejo Comunitario Mayor de la Asociación Campesina Integral del Atrato (Cocomacia), la Asociación de Consejos Comunitarios del Bajo Atrato (Asocoba), el Foro Interétnico Solidaridad Chocó (FISCH) y otros, contra la Presidencia de la República y otros. Sentencia T-622/16, de 2016. Principio de precaución ambiental y su aplicación para proteger el derecho a la salud de las personas-Caso de comunidades étnicas que habitan la cuenca del río Atrato y manifiestan afectaciones a la salud como consecuencia de las actividades mineras ilegales. Referencia: Expediente T-5.016.242. Véase http:// www.corteconstitucional.gov.co/?cbh (consulta el 1 de marzo de 2019).

16 Corte Suprema de Justicia. Sentencia STC. 4360-2018. M. P. Luis Armado Tolosa Villabona. Bogotá, D.C., 5 de abril de 2018. Este pronunciamiento del Alto Tribunal sigue la misma línea de la Sentencia T-622/2016 de la Corte Constitucional, ibid. 
artístico. d) Promover el uso racional de los recursos naturales, salvaguardando su capacidad de renovarse y mantener la estabilidad ecológica, respetando el principio de solidaridad intergeneracional. e) Actuar en cooperación con las autoridades locales, promoviendo la calidad ambiental de los asentamientos rurales y la vida urbana, particularmente en el nivel arquitectónico y en lo que respecta a la protección de zonas históricas. f) Promover la integración de los objetivos ambientales en las diversas políticas de carácter sectorial. g) Promover la educación ambiental y el respeto a los valores ambientales. h) Asegurar que la política fiscal haga que el desarrollo sea compatible con la protección del medio ambiente y la calidad de vida. La noción de que la Naturaleza tiene derechos y valor se reitera en las normas internacionales de muchos países (Boyd, 2017: 99).

Estos avances judiciales y normativos en diferentes partes del mundo e incluso a nivel constitucional en algunos de los Estados miembros de la Unión Europea constituyen, sin duda, un buen precedente inspirador de una tendencia que podría extenderse al resto del territorio de la UE, mediante un ejercicio hermenéutico del patrimonio jurídico de la UE, de modo que sirva de base para justificar el reconocimiento de los derechos de la Naturaleza a través de las obligaciones de protección del medio ambiente.

Si bien es verdad que la Unión Europea y sus Estados miembros comparten un sistema de integración único y particular, difícilmente comparable con los sistemas jurídicos antes mencionados, cabe replantear en qué medida el sistema de la Unión Europea puede incorporar estas tendencias biocéntricas experimentadas en los sistemas constitucionales iberoamericanos. Este planteamiento puede surgir no tanto de una comparativa de sistemas, sino de la situación de la Naturaleza en Europa y de las potencialidades jurídicas existentes en la UE, para propiciar una transición regulatoria del derecho a la Naturaleza a los derechos de la Naturaleza.

\section{LA SITUACIÓN DE LA NATURALEZA EN LA UNIÓN EUROPEA}

Como se mencionaba anteriormente, una de las justificaciones por las cuales existe la posibilidad de una aproximación biocéntrica de la UE en la protección de la Naturaleza es la gran riqueza natural existente en su territorio, pero también su fragilidad expuesta a intereses no siempre convergentes con la protección pretendida (Dunlap, Schmidt y Guerra, 2011). Así, los ejemplos antes analizados sobre el reconocimiento de los derechos de la Naturaleza en diferentes ordenamientos jurídicos y fallos judiciales han respondido a una situación de degradación ambiental. Es por esto importante analizar si también 
en Europa puede darse esta circunstancia y motivar un cambio de paradigma hacia al biocentrismo.

En efecto, Europa alberga una diversidad natural única, con zonas de alta biodiversidad reconocidas a nivel mundial, como el Mediterráneo. En la actualidad, y en particular, la UE goza de normativas medioambientales que figuran entre las más estrictas del mundo, con objetivos claros que orientan la política medioambiental europea a largo plazo (Hovden, 2018: 3-4). Esta ambición ambiental, sin embargo, contrasta con el peso de un modelo de desarrollo basado en los recursos naturales (Alblas, 2018: 141-152). Esto quizá ha provocado, según los científicos López-Bao, Chapron y Epstein, que se hayan "[...] otorgado derechos a entidades no humanas como corporaciones o estados, e incluso se está discutiendo actualmente sobre la personalidad jurídica de los robots, mientras que el debate sobre los derechos de la naturaleza parece en un segundo plano» (Chapron et al., 2019: 1392).

Con todo, la diversidad natural de Europa forma parte de la elaboración regular de informes en el marco de uno de los principales actos jurídicos de la UE sobre la protección de la naturaleza: la Directiva de Hábitats (Chapron et al., 2019: 1392).

Esta directiva, que entró en vigor en 1992, anunció el inicio de acciones firmes e innovadoras de la UE en materia de conservación de la Naturaleza. La red Natura 2000 de zonas protegidas es el instrumento fundamental. Esta red pretende, llevando el concepto de conservación de la Naturaleza más allá de las reservas naturales, alcanzar un equilibrio entre la actividad humana y la vida silvestre en un paisaje vivo y cambiante. Actualmente, representa el $18 \%$ de la superficie europea terrestre y el $6 \%$ de la marina, protegiendo a más de un millar de especies y más de 27000 espacios naturales en Europa ${ }^{17}$. Gracias a ello, la Unión Europea alberga ahora la mayor red mundial de áreas protegidas del mundo, la Red Natura 2000, que abarca casi la quinta parte del territorio continental europeo.

La Directiva de Hábitats identifica los recursos naturales que corren más peligro y que son más valiosos. Figuran en la lista alrededor de doscientos hábitats y más de un millar de especies de animales y plantas, y el objetivo es garantizar su sostenibilidad a largo plazo, lo que se conoce como «estado de conservación favorable».

Las dos vías principales para lograr estos objetivos son la red Natura 2000 de zonas de conservación, que incorpora las áreas creadas en virtud de la Directiva de Aves anterior, y un estricto régimen de protección de las especies.

17 Consúltese la web oficial de la red Natura 2000 en http://ec.europa.eu/environment/ nature/natura2000/data/index_en.htm (consulta el 1 de marzo de 2019). 
Natura 2000 no es una red de reservas naturales. Se basa en un principio más amplio de conservación y uso sostenible que aspira a la coexistencia armoniosa de la actividad humana y la naturaleza. Se estimulan actividades económicas como la agricultura, el turismo, la pesca o la silvicultura, siempre que se desarrollen de manera favorable a la Naturaleza.

A pesar de este marco normativo de protección, la pérdida de diversidad biológica se ha acelerado a niveles sin precedentes en Europa, como ocurre también en otras partes del mundo. Se ha estimado que un $42 \%$ de los mamíferos europeos, un 15\% de las aves y el $45 \%$ de las mariposas y los reptiles se encuentran en riesgo de extinción (European Environment Agency, 2018b). Según la Agencia Europea del Medio Ambiente (AEMA/EEA), la necesidad de conservar y mejorar el capital natural es un objetivo político explícito en la Estrategia de Biodiversidad de la UE para 2020 (European Commission, 2011) y su Séptimo Programa de Acción Ambiental (European Environment Agency, 2018b). Con lo cual, se plantea si la protección actual, a pesar de ser una de las más protectoras del medio ambiente, es la más adecuada de acuerdo con el marco jurídico actualmente establecido.

\section{LA CONSERVACIÓN DE LA NATURALEZA EN LA UE: DEL DERECHO A LA NATURALEZA A LOS DERECHOS DE LA NATURALEZA}

Las primeras políticas de protección de la Naturaleza a escala de la UE entraron en vigor hace cuarenta años con la adopción en 1979 de la Directiva 79/409/CEE, de 2 de abril, relativa a la conservación de las aves silvestres. Con esta lejana Directiva de Aves, la UE sentó las bases de la que sería su política de "acciones específicas» en materia medioambiental, articulando la que sería una de las normas ambientales más estrictas del mundo (Baker, 2007: 297-317).

La Directiva sobre aves silvestres proporciona una amplia protección para las aves silvestres de Europa. Identifica 194 especies y subespecies de aves silvestres como especies en peligro de extinción que requieren medidas especiales de conservación. Los Estados miembros deben crear Áreas de Protección Especial (ZEPA) para proteger las especies de aves silvestres en peligro de extinción. Las ZEPA forman parte de los sitios Natura 2000, y están diseñadas para salvaguardar los lugares donde viven las aves y para protegerlos de las perturbaciones. La Directiva sobre aves silvestres también prohíbe las actividades, con algunas excepciones limitadas, que amenazan a las aves silvestres, como tomar huevos de aves, destruir nidos de aves, capturar o matar deliberadamente aves o comerciar con aves vivas o muertas. Para detener la 
pérdida de biodiversidad también limita el número de especies de aves que se pueden cazar, y prescribe cómo se puede realizar la caza.

Los responsables de la formulación de políticas ampliaron esta estrategia con la Directiva de Hábitats de 1992, que obligó a los Estados miembros a designar zonas especiales de conservación.

El objetivo de la Directiva Hábitats es contribuir a garantizar la biodiversidad mediante la conservación de los hábitats naturales y de la fauna y flora silvestres en el territorio de la Unión. En el marco de dicha directiva, se establece una red europea coherente de zonas especiales de conservación (en lo sucesivo, "ZEC») para garantizar el mantenimiento o, en su caso, el restablecimiento, en un estado de conservación favorable, de los tipos de hábitats naturales y de los hábitats de las especies de que se trate en su área de distribución natural. Dentro de las ZEC, los Estados miembros deben evitar el deterioro de los hábitats naturales y de los hábitats de especies, así como las alteraciones que repercutan en las especies que hayan motivado la designación de las zonas. Cualquier plan o proyecto que, sin tener relación directa con la gestión del lugar o sin ser necesario para la misma, pueda afectar de forma apreciable a los citados lugares, se someterá a una adecuada evaluación de sus repercusiones en el lugar, teniendo en cuenta los objetivos de conservación de dicho lugar. Las autoridades nacionales competentes solo se declararán de acuerdo con un plan o proyecto tras haberse asegurado de que no causará perjuicio a la integridad del lugar en cuestión y, si procede, tras haberlo sometido a información pública.

Con la entrada en vigor del Tratado de Lisboa, el 1 de diciembre de 2009, la protección ambiental figura tanto en el Tratado de la Unión Europea (TUE) como en su Tratado de Funcionamiento de la Unión Europea (TFUE), donde el medio ambiente es una de las competencias compartidas entre la Unión Europea y los Estados miembros (art. 4.3 TFUE); así como en el art. 37 de la Carta de los Derechos Fundamentales de la Unión Europea (las políticas de la Unión integrarán y garantizarán con arreglo al principio de desarrollo sostenible un alto nivel de protección del medio ambiente y la mejora de su calidad). Sin embargo, a pesar de lo que pueda parecer, no se trata de un verdadero derecho - como señalan las explicaciones de la Carta-, sino de un principio basado en los arts. 2, 6 y 174 del antiguo Tratado constitutivo de la Comunidad Europea (actuales arts. 3.3 TUE y 11 y 191 TFUE), que se inspira en las disposiciones de determinadas constituciones nacionales.

A pesar de los avances producidos en muchas partes del mundo, analizados anteriormente de forma sucinta, en la región europea aún no ha habido ni un reconocimiento jurídico formal ni siquiera algún pronunciamiento judicial al respecto, a pesar de que, de acuerdo con el Eurobarometer (2010), la 
naturaleza es importante para la ciudadanía europea: más del $80 \%$ piensa que la pérdida de la Naturaleza en su país es un problema grave ${ }^{18}$.

El reconocimiento de los llamados "Derechos de la Naturaleza», como instrumento para asegurar los derechos humanos básicos, podría constituir el argumento suficiente, aunque desde una perspectiva antropocéntrica, para proceder al reconocimiento de los Derechos de la Naturaleza.

El principal obstáculo es que el sistema de los derechos humanos es, a lo sumo, de un carácter más epistemológico que efectivo, sobre todo si se considera que la UE no es una organización internacional que se centre en la protección de los derechos humanos, como pueda ser, por ejemplo, la Organización de Estados Americanos, a través del Sistema interamericano de Derechos Humanos. No obstante, el vínculo UE, a través de su Carta de Derechos Humanos y el Consejo de Europa, a través del Convenio Europeo de derechos y libertades fundamentales, constituye una buena base para reforzar este sistema de derechos en la UE, especialmente contribuyendo a un posible reconocimiento de los derechos de la Naturaleza. La cuestión es plantearse si para el reconocimiento de los derechos de la Naturaleza es necesario a priori tener un fundamento sólido de derechos humanos.

En todo caso, resulta interesante, a continuación, abordar los factores tendenciales, que pueden influir en esta posible transición hacia el biocentrismo, partiendo del actual marco de protección jurídica de la Naturaleza en la UE para pasar a analizar las posibles opciones en el reconocimiento de los derechos de la Naturaleza en la UE, como son las de orden procesal y las de orden sustantivo.

\section{FACTORES TENDENCIALES DEL ACTUAL MARCO DE PROTECCIÓN JURÍDICA DE LA NATURALEZA EN LA UE}

Si bien los derechos de la Naturaleza no encuentran, actualmente, un reconocimiento expreso en el ordenamiento jurídico de la UE, sí que pueden apuntarse unos factores tendenciales hacia un giro biocéntrico de reconocimiento de los derechos de la Naturaleza. Al igual que ha sucedido en otros ordenamientos jurídicos, anteriormente analizados, en los que a pesar de no

18 Véase Eurobarometer 74, 2010 Public Opinion in the European Union. Report Fieldwork: November 2010. También consúltese «Citizens' images and values of nature in Europe A survey in nine EU Member States», Netherlands Environmental Assessment Agency, The Hague, 2016 y TNS Political \& Social (2015), Attitudes of European towards biodiversity, Flash Eurobarometer n. 436. European Commission, Brussels. 
estar reconocidos estos derechos, la necesidad de salvaguardar determinados recursos naturales ha requerido un enfoque de protección diferente del antropocéntrico.

En la actualidad, la protección del medio ambiente en la UE se regula en los arts. 11 y 191 a 193 del TFUE. De acuerdo con estas bases jurídicas, la UE es competente para actuar en todos los ámbitos de la política de medio ambiente, como la contaminación del aire y el agua, la gestión de residuos y el cambio climático. No obstante, su ámbito de actuación se ve limitado por el principio de subsidiariedad y por el requisito de unanimidad en el Consejo en los ámbitos de asuntos fiscales, ordenación territorial, utilización del suelo, gestión cuantitativa de los recursos hídricos, elección de fuentes de energía y estructura del abastecimiento energético.

No obstante, el principio de subsidiariedad puede impulsar la acción biocéntrica, pudiendo funcionar como una salvaguarda para la protección de la Naturaleza, junto con la posibilidad de las acciones adicionales de protección que los Estados miembros puedan adoptar en virtud del art. 193 TFUE. Todo ello considerando que las medidas implementadas por los Estados miembros a partir de la normativa desarrollada en el ámbito de la política ambiental de la UE no han sido satisfactorias para favorecer el cumplimiento de las distintas directivas adoptadas en el seno de la Política Ambiental Europea. Según el último Informe de la Comisión Europea, publicado en julio de 2019, de los 644 casos de incumplimiento, que la Comisión inició en 2018, el medio ambiente sigue en tercer lugar con 73 expedientes, después de los asuntos relativos a mercado interior, industria, emprendedores y PYME, sobre movilidad y transporte. Además de las 339 quejas que recibió la Comisión en 2018, 142 eran relativas a la protección de la Naturaleza, siendo el sector ambiental en el que más irregularidades de aplicación y cumplimiento se han registrado (European Commission, 2019).

Este grado de incumplimiento de los Estados miembros de la regulación jurídica ambiental de la UE plantea la necesidad de considerar la intervención del principio de subsidiariedad para procurar no solo la protección del medio ambiente, sino también el cumplimiento de los objetivos de la integración europea, como resorte de garantía final de la protección del medio ambiente, tal y como se refiere el art. 5.4 TUE cuando establece que la UE contribuirá al desarrollo sostenible del planeta.

Asimismo, el art. 37 de la Carta de los Derechos Fundamentales de la Unión Europea se refiere a que las políticas de la Unión integrarán y garantizarán con arreglo al principio de desarrollo sostenible un alto nivel de protección del medio ambiente y la mejora de su calidad. Sin embargo, a pesar de lo que pueda parecer, no se trata de un verdadero derecho - como señalan las 
explicaciones de la Carta-, sino de un principio basado en los arts. 2, 6 y 174 del antiguo Tratado constitutivo de la Comunidad Europea (actuales arts. 3.3 TUE y 11 y 191 TFUE) que se inspira en «las disposiciones de determinadas constituciones nacionales».

La legislación medioambiental de la UE contribuye a la consecución de los siguientes objetivos de la política de la UE sobre el medio ambiente ${ }^{19}$, establecidos en el art. 191 del TFUE: preservar, proteger y mejorar la calidad del medio ambiente; protector de la salud humana; utilización prudente y racional de los recursos naturales; y promover medidas a nivel internacional para tratar con organizaciones regionales o mundiales los problemas medioambientales, y en particular la lucha contra el cambio climático.

No obstante lo anterior, lo más próximo a un intento de incorporar la perspectiva biocéntrica es el art. 13 del TFUE, introducido por el Tratado de Lisboa, que establece que:

Al formular y aplicar las políticas de la Unión en materia de agricultura, pesca, transporte, mercado interior, investigación y desarrollo tecnológico y espacio, la Unión y los Estados miembros tendrán plenamente en cuenta las exigencias en materia de bienestar de los animales como seres sensibles, respetando al mismo tiempo las disposiciones legales o administrativas y las costumbres de los Estados miembros relativas, en particular, a ritos religiosos, tradiciones culturales y patrimonio regional.

Es decir, de acuerdo con esta disposición, se articula como uno de los principios que informan el orden constitucional europeo considerar a los animales «seres sensibles» $\mathrm{y}$ «sintientes».

Esta disposición no es novedosa, puesto que procede, con algunas modificaciones, del Tratado de Ámsterdam de 1997, que había incluido un Protocolo Adicional sobre la materia, el Protocolo núm. 33 del texto consolidado ${ }^{20}$, que

19 Art. 37 de la Carta de los Derechos Fundamentales. Véase la Carta de los Derechos Fundamentales de la Unión Europea (DO C 202 de 7.6.2016, pp. 389-405) y también el Informe de la Comisión al Parlamento Europeo, al Consejo, al Comité Económico y Social Europeo y al Comité de las Regiones: Informe de 2015 sobre la aplicación de la Carta de los Derechos Fundamentales de la UE [COM(2016) 265 final de 18.5.2016].

20 Versión consolidada del Tratado Constitutivo de la Comunidad Europea publicada en el Diario oficial c 321e de 29 diciembre de 2006. Según el anterior redactado del Protocolo 33: las Altas Partes Contratantes, deseando garantizar una mayor protección y un mayor respeto del bienestar de los animales como seres sensibles, han convenido en la disposición siguiente, que se incorporará como anexo al Tratado consti- 
sería finalmente modificado posteriormente por el Tratado de Lisboa, convirtiendo su contenido en una de las disposiciones iniciales del TFUE.

Con esta disposición, la UE tiene por objeto evitar a los animales todo dolor o sufrimiento innecesario y obligar tanto a los dueños como a los cuidadores de animales a respetar unos requisitos mínimos de bienestar (Tribunal de Cuentas Europeo, 2018). Este es, sin duda, un primer paso hacia el reconocimiento de los derechos de la Naturaleza en la UE, tal y como se analizará en el próximo epígrafe.

Desde la lejana Directiva 79/409/CEE, de 2 de abril, relativa a la conservación de las aves silvestres ${ }^{21}$ — que sentó las bases de la que sería su política de "acciones específicas» en materia medioambiental-, la Unión Europea presume de tener «algunas de las normas de medio ambiente más estrictas del mundo» (Baker, 1997: 91-106). En efecto, las directivas de aves y hábitats, aunque no representan la globalidad de la Naturaleza en la UE, sí que protegen, como ya se ha mencionado anteriormente, a casi una quinta parte de la masa terrestre de Europa, unos doscientos humedales, prados y hábitats marinos, y más de mil especies de animales y plantas ${ }^{22}$.

Otro paso significativo viene representado por la adopción del Séptimo Programa Ambiental «Vivir bien, respetando los límites de nuestro planeta ${ }^{23}$, el cual establece una visión para el futuro: que, en 2050, la UE y su ciudadanía viva bien dentro de los límites ecológicos, con una economía circular en la que no se desperdicia nada y donde la naturaleza se valora y se restaura de manera que mejore su capacidad de recuperación ${ }^{24}$. Así, el programa identifica tres ámbitos prioritarios que requieren más acciones dirigidas a proteger la naturaleza y fortalecer la resiliencia ecológica, promover

tutivo de la Comunidad Europea: «Al formular y aplicar las políticas comunitarias en materia de agricultura, transporte, mercado interior e investigación, la Comunidad y los Estados miembros tendrán plenamente en cuenta las exigencias en materia de bienestar de los animales, respetando al mismo tiempo las disposiciones legales o administrativas y las costumbres de los Estados miembros relativas, en particular, a ritos religiosos, tradiciones culturales y patrimonio regional».

21 Directiva 2009/147/CE del Parlamento Europeo y del Consejo, de 30 de noviembre de 2009, relativa a la conservación de las aves silvestres (DO L 20, de 26 de enero de 2010, pp. 7-25).

22 Véase http://ec.europa.eu/environment/nature/legislation/index_en.htm (consulta el 1 de marzo de 2019).

23 Decisión 1386/2013/UE del Parlamento Europeo y del Consejo, de 20 de noviembre de 2013. (DO L 354 de 28.12.2013, p. 171). Para más información: http://ec.europa. eu/environment/pubs/pdf/factsheets/7eap/es.pdf (consulta el 1 de marzo de 2019).

24 Consúltese http://ec.europa.eu/environment/action-programme/ (consulta el 1 de marzo de 2019). 
un crecimiento hipocarbónico, que utilice los recursos de forma eficiente y reducir las amenazas para la salud y el bienestar humanos asociadas a la contaminación, las sustancias químicas y el impacto del cambio climático.

Asimismo, el programa LIFE también ha sido un instrumento propicio para la protección de la Naturaleza en Europa, en la medida en que apoya proyectos medioambientales y de conservación de la Naturaleza en toda la UE, así como en algunos países candidatos, países adherentes y países vecinos. En este sentido, desde 1992, LIFE ha cofinanciado alrededor de 3104 proyectos, contribuyendo, aproximadamente, con 2,2 billones de euros para la protección del medio ambiente. Además, el 15 de febrero de 2019, la Comisión Europea anunció una inversión de 116,1 millones de euros en los últimos proyectos integrados financiados en el marco del programa LIFE ${ }^{25}$.

A pesar de estos logros en la protección de la Naturaleza en la UE, los intereses y prioridades económicas no siempre han sido favorables. Por ejemplo, poco después de asumir el cargo en 2014, la Comisión Europea, a través de su presidente, propuso revisar las normas relativas a la naturaleza en la $U^{26}$ y hacerlas más favorables a los negocios, lo que generó un conflicto interno en la misma Comisión. Con posterioridad, la misma Comisión aprobó, el 27 de abril de 2017, la comunicación «Un plan de acción en pro de la naturaleza, las personas y la economía ${ }^{27}$. Este plan de acción global tiene por objeto mejorar rápidamente la aplicación práctica de las directivas de protección de la naturaleza y acelerar el progreso hacia el objetivo de la UE para 2020 de detener e invertir la pérdida de biodiversidad y de servicios ecosistémicos, pues se reconoce que, si bien las directivas de protección de la naturaleza son adecuadas para los fines perseguidos, es necesario mejorar su aplicación para lograr la protección del "patrimonio natural de Europa». Las quince medidas que se centran en cuatro ámbitos prioritarios: mejorar las orientaciones y los conocimientos y garantizar una mayor coherencia con objetivos socioeconómicos más amplios; impulsar la responsabilidad política y reforzar el cumplimiento; aumentar las inversiones en Natura 2000 y mejorar la utilización de los fondos de la Unión Europea y mejorar la comunicación y la divulgación, y lograr la participación de ciudadanos, partes interesadas y comunidades.

25 Información disponible en: https://ec.europa.eu/environment/efe/content/new-lifefunding-trigger-eur-32-billion-greener-world_es (consulta el 1 de julio de 2019).

26 Consúltese https://ec.europa.eu/commission/sites/cwt/files/vella_en.pdf (consulta el 1 de marzo de 2019).

27 Comunicación de la Comisión al Parlamento Europeo, al Consejo, al Comité Económico y Social Europeo y al Comité de las Regiones, "Un plan de acción en pro de la naturaleza, las personas y la economía» $\{\operatorname{SWD}(2017) 139$ final $\}$. Bruselas, 27.4.2017 COM(2017) 198 final. 
En relación con este plan, el Parlamento Europeo adoptó la Resolución del Parlamento Europeo, de 15 de noviembre de 2017, sobre un plan de acción en pro de la naturaleza, las personas y la economía ${ }^{28}$ en la cual se insta a la Comisión Europea a que presente una nueva propuesta legislativa sobre normas mínimas para el acceso al control jurisdiccional, así como una revisión del Reglamento sobre la aplicación del Convenio de Aarhus a la acción de la Unión, a fin de tener en cuenta la recomendación del Comité de Cumplimiento de dicho Convenio. Esta sería una posibilidad viable, entre otras que a continuación se analizarán, de reconocimiento indirecto de los derechos de la Naturaleza, al igual que ha sido una vía para ciertos Estados del mundo donde no se regulaba la existencia de derechos de la Naturaleza, pero que la jurisprudencia, en cambio, ha permitido desarrollar esta opción de protección de la Naturaleza.

\section{OPCIONES EN EL RECONOCIMIENTO DE LOS DERECHOS DE LA NATURALEZA EN LA UE}

La transición biocéntrica hacia el reconocimiento de los derechos de la Naturaleza en la UE puede articularse mediante la interpretación hermenéutica de los tratados de la UE. En concreto, las posibilidades van desde la determinación de la conceptualización de la Naturaleza, las opciones procesales y sustantivas, y la determinación de la figura de la custodia de protección, como a continuación se procede a analizar.

Estas opciones no son excluyentes, sino que pueden converger conjuntamente hacia el reconocimiento y la tutela de los derechos de la Naturaleza.

\subsection{Reconceptualización de la protección de la Naturaleza: como objeto a sujeto de protección}

La atribución de derechos permite la personalidad legal a un recurso natural, al igual que se atribuyen derechos a las fundaciones, las empresas o a las sociedades mercantiles. En este sentido, en relación a la posibilidad de atribución de derechos de la Naturaleza debería determinarse, a nivel de la UE, qué aspectos, si la naturaleza en general, o partes específicas, pueden ser protegidas y qué ecosistemas, con sus componentes no vivos o físicos de su entorno, deben ser parte de la Naturaleza, considerada una entidad viviente y protegida con derechos.

28 Doc. 2017/2819(RSP). 
Como ya se ha analizado anteriormente, la visión biocéntrica ya se está produciendo, por ejemplo, el caso del reconocimiento de los ríos, como el río Whanganui (Nueva Zelanda), el Ganges (India) y el Atrato (Colombia) como entidades naturales con derechos. Este reconocimiento no solo viene motivado por el valor espiritual o de sacralidad de estos recursos, sino sobre todo para protegerlo de intensos procesos de contaminación industrial, urbanización y agricultura sin control. Este mismo argumento, junto al valor ambiental de determinados recursos naturales en Europa, especialmente los integrados en la Red Natura 2000, permitiría avanzar en el reconocimiento de una protección biocéntrica. Por ejemplo, el parque de los lagos de Plitvice en Croacia ${ }^{29}$, un paraje natural, que fue candidato a ser una de las siete maravillas naturales del mundo en el 2011 o ríos como el Volga, el Danubio, el Rin, entre muchos otros, podrían beneficiarse de cambio biocéntrico en la medida en que tan solo el $40 \%$ de los ríos, acuíferos, humedales y lagos de Europa están en un estado saludable, según el Informe sobre el «Estado del Agua» de la AEMA de 2018 (European Environment Agency, 2018a). La situación crítica en la que se encuentran la mayor parte de las fuentes hídricas europeas exige un replanteamiento de cómo mejorar su protección.

Asimismo, es importante tener en cuenta que la naturaleza debe ser vista como un todo y se pueden reconocer los derechos a determinados ríos europeos de especial importancia ambiental, pero esto solo debe ser el primer paso para otorgar a la Naturaleza en su totalidad un estatus jurídico con personalidad jurídica propia. Por lo tanto, la definición de Naturaleza a nivel de la UE debería ser modelada desde la definición básica de un ecosistema hacia su consideración de comunidad de convivencia biológica, con organismos, ya sean componentes no vivos o físicos de su entorno, con independencia de que en el proceso de cambio el avance se produzca en el reconocimiento sectorial de derechos a diferentes recursos naturales, que, por su valor ecológico y su fragilidad, deben priorizarse en su protección.

Esta es una de las opciones que podrían emplearse dentro de la UE para avanzar en esta transformación de la protección ambiental de carácter biocéntrico, es decir, considerar a la Naturaleza como una entidad viviente, de acuerdo con una interpretación in extenso del art. 13 del TFUE. Este reconocimiento permitiría analizar las opciones procesales y sustantivas, para fundamentar la transición hacia este nuevo enfoque biocéntrico de protección ambiental, sin necesidad de proceder a una modificación del derecho originario de la UE.

29 Este parque está situado en la región de Lika (Croacia), y se compone de 16 lagos interconectados y 92 manantiales y cascadas que ocupan una superficie cercana a 30000 hectáreas, 22000 de masa forestal. 


\subsection{Las opciones procesales de protección de los derechos ambientales}

Una reconceptualización del estatuto jurídico de cómo proteger a la $\mathrm{Na}$ turaleza, en términos de su consideración equiparable a una persona física o jurídica, puede producirse también a través de las opciones procesales de los arts. 263 y 265 TFUE, que permiten la posibilidad de emprender acciones judiciales de revisión, por parte de personas físicas y jurídicas, frente a determinados actos normativos. Las consecuencias de anular una acción, en virtud del art. 263 TFUE, es que el acto sea declarado nulo. Es decir, las acciones interpuestas ante los tribunales de la UE por personas físicas o jurídicas contra medidas de la UE adoptadas con arreglo al derecho ambiental pueden ser anuladas en virtud del art. 263, apdo. 4, TFUE, que establece que toda persona física o jurídica podrá interponer recurso contra los actos de los que sea destinataria o que la afecten directa e individualmente y contra los actos reglamentarios que la afecten directamente y que no incluyan medidas de ejecución. En su jurisprudencia, el TJUE ha ido interpretando las condiciones establecidas en esa disposición y en sus predecesoras, y el asunto paradigmático en lo que respecta a la interpretación del concepto de "afectación directa» es el asunto Plaumann $^{30}$, en el que el tribunal concluyó que quienes no sean destinatarios de una decisión solo pueden alegar que esta les afecta individualmente cuando dicha decisión les atañe debido a ciertas cualidades que les son propias o a una situación de hecho que les caracteriza en relación con cualesquiera otras personas y, por ello, les individualiza de una manera análoga a la del destinatario. El TJUE ha desarrollado a lo largo del tiempo su jurisprudencia en el asunto Plaumann aplicándola y adaptándola a circunstancias legales o materiales específicas, es decir, con independencia de la naturaleza del recurrente ${ }^{31}$.

El Tratado de Lisboa amplió el alcance de las normas sobre la jerarquía en los recursos de anulación interpuestos por particulares, añadiendo al final del apdo. 4 el texto [...] y contra los actos reglamentarios que la afecten directamente y que no incluyan medidas de ejecución. Cuando se cumplen esas condiciones, no es necesario que el recurrente demuestre que el acto impugnado le afecta individualmente.

30 Sentencia del Tribunal de Justicia de 15 de julio de 1963, Plaumann/Comisión, 25/62, EU:C:1963:17.

31 Por ejemplo, consultar la Sentencia del Tribunal de Justicia (Gran Sala) de 28 de abril de 2015, P, T \& L Sugars Ltd y Sidul Acúcares/Comisión, C-456/13, EU:C:2015:284, apdo. 63; Sentencia del Tribunal de Justicia (Gran Sala) de 3 de octubre de 2013, Inuit Tapiriit Kanatami y otros/Parlamento y Consejo, C-583/11 P, EU:C:2013:625, apdo. 72; y Sentencia del Tribunal de Justicia (Gran Sala) de 19 de diciembre de 2013, Telefónica/Comisión, C-274/12 P, EU:C:2013:852, apdo. 46. 
Esta posibilidad, junto a la adopción de un reglamento, similar al Reglamento de Aarhus ${ }^{32}$, permitiría a la Naturaleza, como entidad con capacidad jurídica, realizar una revisión administrativa a través de una persona física o jurídica. No obstante, para articular esta posibilidad, habría que establecer reglas separadas sobre quién podría actuar en nombre de la Naturaleza: por ejemplo, determinando quién podría actuar como directamente afectado por su posición, una persona u organización tutora, en nombre de la Naturaleza, con el fin de reforzar y hacer cumplir las normas ambientales sustantivas, ya existentes en la UE, tal y como pretende el anteriormente analizado «Plan de acción en pro de la naturaleza, las personas y la economía». En este sentido, seguramente una enmienda de procedimiento podría ser comparativamente más fácil de implementar en comparación al reconocimiento de un derecho ambiental sustantivo, puesto que las obligaciones procesales son claras, explícitas y objetivas.

En este orden de ideas, el TJUE ha hecho referencia al art. 9, apdo. 3, del Convenio de Aarhus el 25 y al art. 47 de la Carta de los Derechos Fundamentales de la Unión Europea para interpretar que estos se oponen a una normativa procesal nacional que impide que una organización ecologista, debidamente constituida y que opera respetando los requisitos previstos en el derecho nacional, acceda a procedimientos administrativos o judiciales en el sentido del art. 9, apdo. 3, de dicho convenio para impugnar actos adoptados por la autoridad competente en un procedimiento administrativo sustanciado con arreglo a disposiciones de derecho nacional en aplicación de una directiva ${ }^{33}$.

Siguiendo este parámetro jurisprudencial, la acción ciudadana ha contribuido a la adopción de importantes sentencias del Tribunal de Justicia de la UE. Por ejemplo, en 2011, la jurisprudencia apoyó a una ONG eslovaca que pedía reforzar la protección de los osos pardos, dictaminando que tenía derecho a ser oída ${ }^{34}$. En este caso, se planteaba si una asociación de protección ambiental puede ser una "parte» en los procedimientos administrativos, en particular, dirigidos a la concesión de excepciones al sistema de protección para especies como el oso pardo, que se menciona en el Anexo IV (a) de la Directiva Hábitats. El tribunal concluyó que la disputa estaba

32 Reglamento (CE) 1367/2006 del Parlamento Europeo y del Consejo, de 6 de septiembre de 2006, relativo a la aplicación, a las instituciones y a los organismos comunitarios, de las disposiciones del Convenio de Aarhus sobre el acceso a la información, la participación del público en la toma de decisiones y el acceso a la justicia en materia de medio ambiente (DO L 264, 25.9.2006, pp. 13-19).

33 Sentencia del Tribunal de Justicia (Sala Segunda) de 20 de diciembre de 2017, Protect Natur, C664/15, EU:C:2017:987.

34 Conclusiones del abogado general Sharpston, Lesoochranárske zoskupenie, C-240/09, EU:C:2010:436. 
dentro del alcance de la legislación de la UE, a pesar del hecho de que la Comunidad, en la declaración de competencia declaró que es responsabilidad de los Estados miembros cumplir las obligaciones establecidas en el art. 9 (3) del Convenio de Aarhus. Aquí, el tribunal enfatizó que cuando una disposición puede aplicarse tanto a situaciones que están dentro del alcance de la ley nacional como a situaciones que están dentro del alcance de la legislación de la UE, es de interés de esta última que, para prevenir futuras diferencias de interpretación, esa disposición debe ser interpretada uniformemente, cualesquiera que sean las circunstancias en las que se aplique. Por lo tanto, el tribunal decidió que es competente para interpretar las disposiciones del art. 9 (3) del Convenio de Aarhus y, en particular, para decidir si tienen efecto directo o no. Así, mediante la aplicación del Convenio de Aarhus, la custodia de los derechos de la Naturaleza, o al menos de algunos de sus elementos, puede ser garantizada mediante el reconocimiento procesal de las asociaciones ambientalistas.

De modo que el público europeo, ya sean particulares, grupos o empresas, desempeña un papel esencial a la hora de vigilar la manera en que se pone en práctica la legislación de la UE, y en ese tránsito al reconocimiento de los derechos de la Naturaleza. No obstante, a su vez se observan otras tendencias, cuanto más preocupantes: el caso de que las empresas demanden a los gobiernos por intentar proteger a las personas o la Naturaleza, como es el caso de Bayer Syngenta contra la prohibición de la UE de tres pesticidas neonicotinoides, relacionados con la muerte de millones de abejas ${ }^{35}$.

Esto conduce a considerar si esta actuación procesal podría funcionar aisladamente o bien, en conjunto con la opción de reconocer derechos sustantivos para la Naturaleza en el derecho de la UE. Lo que es cierto es que las acciones que dañan la Naturaleza en violación de los derechos de las personas permitirían no solo la actividad de representación, sino también forzar el cumplimiento de las normas ambientales. No obstante, hay un problema de reconciliación entre los derechos humanos y los derechos que integrarían los derechos de la Naturaleza. Así, la misma Comisión Europea se refiere a que «en el ámbito de la protección de la naturaleza, ya que en dicho ámbito puede ser difícil argumentar que las decisiones, actos u omisiones de las autoridades

35 Recurso interpuesto ante el Tribunal General de la Unión Europea el 14 de agosto de 2013, Syngenta Crop Protection y otros/Comisión, T-451/13. También recurso interpuesto ante el Tribunal General de la Unión Europea el 19 de agosto de 2013, Bayer CropScience/Comisión, T-429/13. 
públicas puedan afectar a los derechos específicos de las personas, como los relacionados con la salud de las personas» ${ }^{36}$.

Es decir, para la determinación de los derechos de la Naturaleza, puede consultarse, por ejemplo, el caso boliviano, cuya legislación estableció como derechos de la Naturaleza: el derecho a la vida, a la diversidad, al agua pura y al aire limpio, el derecho al equilibrio y la restauración (Gudynas, 2011: 239). O incluso a derechos similares relacionados en la Declaración Universal de los Derechos de la Naturaleza ${ }^{37}$. Sin embargo, estos derechos son demasiado vagos e inciertos y accionarlos, a través de la protección de los derechos humanos, es complicado y, de nuevo, supondría una sectorialización de la Naturaleza.

En este sentido, además del reconocimiento de la Naturaleza, como persona jurídica, y de la defensa procesal de sus derechos, se puede considerar una tercera opción, la de establecer un régimen de custodia. Es decir, en lugar de reconocer directamente derechos sustantivos a la Naturaleza, establecer obligaciones humanas — no derechos humanos- de protección.

\subsection{La custodia de protección de la Naturaleza}

La figura de la «custodia de protección» de la Naturaleza es una herramienta de conservación que tiene como objetivo implicar a la sociedad y a las administraciones, como responsables de conservar y proteger la Naturaleza (Knauß, 2018: 703). El enfoque de los derechos justifica las obligaciones con la Naturaleza más allá de los intereses humanos, centrándose en la idea de la Tierra como un sistema y un proceso no lineal. La integridad de los elementos y procesos naturales se presenta como la razón explícita de una administración humana responsable hacia la Tierra. Esta línea argumental está en consonancia con la idea de la Red Natura 2000.

La responsabilidad de la custodia plantea quién debe o puede actuar en nombre de la Naturaleza, para que pueda presentar una reclamación para proteger la Naturaleza. En este sentido, la UE debe permitir que la ciudadanía actúe en nombre de la Red Natura 2000, especialmente de las organizaciones que tengan conocimiento del ecosistema, un interés general en su bienestar y que pueda representarlo con precisión en los procedimientos (Fish, 2013: 10). Así, las organizaciones no gubernamentales en la Unión Europea ya han

36 Doc. C(2017) 2616 final. Disponible en línea en: https://ec.europa.eu/transparency/ regdoc/rep/3/2017/ES/C-2017-2616-F1-ES-MAIN-PART-1.PDF (consulta el 1 de marzo de 2019).

37 Texto disponible en: http://rio20.net/propuestas/declaracion-universal-de-los-derechos-de-la-madre-tierra/ (consulta el 1 de marzo de 2019). 
actuado durante muchos años como una voz que la Naturaleza no tiene, a pesar de las limitaciones de acceso a la justicia ante el TJUE (Ruiz de Apodaca Espinosa, 2018: 1-53; García Ureta, 2005: 190).

En efecto, actualmente, de acuerdo con el Reglamento 1367/2006, relativo a la aplicación, a las instituciones y a los organismos comunitarios, de las disposiciones del Convenio de Aarhus, una organización no gubernamental debe cumplir con cuatro requisitos para actuar en protección de la Naturaleza: debe ser una persona jurídica independiente y sin fines de lucro con el objetivo principal de promover la protección del medio ambiente. Además, debe demostrar su antigüedad por más de dos años y perseguir activamente sus objetivos ambientales. Finalmente, el objeto de la revisión interna ante un organismo de la UE debe ser cubierto el objetivo de la organización ${ }^{38}$.

A pesar de esta regulación, no se incluye el derecho de acceso a la justicia en materia ambiental. Aun así, los criterios del Reglamento de Aarhus ya proporcionan un buen filtro para la articulación de los derechos de la naturaleza en la UE. Con pequeños ajustes, podrían ser apropiados para que las ONG actúen en nombre de la Naturaleza en los procedimientos judiciales ante el TJUE, siempre y cuando, como se analiza más adelante, la UE garantice esta posibilidad. Los tres criterios son esenciales y podrían permanecer: el objetivo de la protección del medio ambiente es una necesidad, y la existencia de dos años garantiza que la ONG sea un tanto competente, establecida y organizada. Con estos criterios se entiende que la ONG está persiguiendo activamente objetivos ambientales y muestra que tiene una intención genuina y sincera de actuar en interés de la naturaleza. Por estas razones, las ONG son los actores capaces de desempeñar un papel crucial de administrador en un marco de los derechos de la Naturaleza.

\section{AVANCES EN LA JURISPRUDENCIA DEL TJUE}

A nivel jurisprudencial, la tendencia hacia un enfoque biocéntrico de reconocimiento de los derechos de la Naturaleza, aunque tímido, se ha producido al margen de la existencia de un marco jurídico de reconocimiento expreso. En concreto, el 17 de abril de 2018, el Tribunal de Justicia confirmó la ilegalidad del aumento de las talas en el bosque polaco de Bialowieza ${ }^{39}$. El caso se remonta a 2016, cuando el Gobierno polaco permitió la tala a escala

38 Reglamento de Aarhus, cit. supra, art. 11.

39 Sentencia del Tribunal de Justicia de la Unión Europea de 17 de abril de 2018, Comisión/Polonia (Bosque de Białowieża), C-441/17, EU:C:2018:593. 
industrial del bosque, considerado el último bosque primario de Europa y declarado Patrimonio de la Humanidad por la Unesco. Bialowieza, inscrito en la Lista del Patrimonio Mundial de la Unesco en 1979, se divide entre Polonia y Bielorrusia, y cuenta con bosques arcaicos de hoja perenne y caduca. Este es un espacio único en su género para la conservación de la biodiversidad y alberga la mayor población de bisonte europeo, cerca de 700 ejemplares, convirtiéndose en una especie animal emblemática de la región (Hunka, De Groot y Biela, 2009: 430).

En este caso, el Tribunal de Justicia establece que la Directiva sobre los hábitats impone a los Estados miembros una serie de obligaciones y de procedimientos específicos, con el fin de garantizar el mantenimiento o, en su caso, el restablecimiento, en un estado de conservación favorable, de los hábitats naturales y de las especies de fauna y flora silvestres que presenten un interés para la Unión, a fin de alcanzar el objetivo más general, consistente en garantizar un nivel elevado de protección del medio ambiente respecto a los lugares protegidos en virtud de la directiva. Así, la autorización de un plan o de un proyecto solo puede concederse con la condición de que las autoridades competentes hayan adquirido, en la fecha en que se adopte la decisión que autoriza la realización del proyecto, la certidumbre de que el mismo no tiene efectos perjudiciales duraderos para la integridad del lugar afectado.

El Tribunal de Justicia señaló que, al no disponer de todos los datos pertinentes para evaluar las incidencias de las operaciones de gestión forestal activa en cuestión sobre la integridad del lugar Natura 2000 Puszcza Białowieska, las autoridades polacas no llevaron a cabo una evaluación apropiada de estas incidencias antes de adoptar la Decisión de 2016 y la Decisión 51, de modo que incumplieron su obligación derivada de la Directiva sobre los hábitats. A este respecto, el Tribunal de Justicia subraya que la evaluación de las incidencias realizada por las autoridades polacas en 2015 no podía disipar toda duda científica acerca de los efectos perjudiciales de la Decisión de 2016 en el lugar Natura 2000 Puszcza Białowieska.

A continuación, el Tribunal de Justicia examina, en concreto, si las operaciones de gestión forestal pueden conllevar efectos perjudiciales para las especies y hábitats protegidos en el lugar Natura 2000 Puszcza Białowieska $y$, en consecuencia, menoscabar la integridad de este lugar. El Tribunal de Justicia declara a este respecto que las decisiones impugnadas no comportan restricciones relativas a la edad de los árboles o a las poblaciones forestales contempladas por estas operaciones, en particular según el hábitat en el que se encuentren. Además, estas decisiones permiten la tala de árboles por razones de «seguridad pública», sin la menor precisión en cuanto a las condiciones concretas que justifican una tala por esas razones. Según el Tribunal de Justicia, la argumentación desarrollada por Polonia no permite considerar que las 
operaciones de gestión forestal puedan estar justificadas por la necesidad de luchar contra la propagación del Ips typographus.

Este caso, a pesar de que no se reconozcan expresamente los derechos de la Naturaleza, sí que es un pronunciamiento importante, pues se prioriza el valor intrínseco de este espacio natural por encima de otros intereses en presencia, acercándose a los planteamientos de protección de la naturaleza per se.

\section{DEL RECONOCIMIENTO DE LOS DERECHOS DE LA CIUDADANÍA EUROPEA AL RECONOCIMIENTO DE LOS DERECHOS DE LA NATURALEZA: EL CONVENIO DE AARHUS Y LA INICIATIVA CIUDADANA EUROPEA}

De las posibles opciones para promover el reconocimiento de los derechos de la Naturaleza o algunos de sus componentes, la que tiene más desarrollos y potencialidades en la UE es la procedimental: ya sea garantizando el acceso a la justicia en temas ambientales para proteger a la Naturaleza (vía directa) o bien garantizando los derechos humanos de la ciudadanía europea afectada por la degradación ambiental para proteger a la Naturaleza (vía indirecta).

Estos avances, en parte, han sido posibles gracias al incremento de información sobre la situación del medio ambiente en la UE, favoreciendo la activación de los procesos de participación en la UE, que han permitido un reclamo desde la ciudadanía para la transición hacia un nuevo modelo de protección del medio ambiente, que supere antiguos cánones antropocentristas.

En concreto se apuntan, a continuación, los avances en este sentido: uno, el incremento de la democracia ambiental para proteger a la Naturaleza y dos, la iniciativa ciudadana europea para la Naturaleza, junto con la propuesta de Directiva sobre derechos de la Naturaleza en la UE y de la convocatoria de un Tribunal Europeo de los Derechos de la Naturaleza.

\section{INCREMENTAR LA DEMOCRACIA AMBIENTAL PARA PROTEGER LA NATURALEZA}

El Convenio de Aarhus es un instrumento emblemático en materia de democracia ambiental. El Convenio y su protocolo sobre registros de emisiones y transferencias de contaminantes son los únicos instrumentos internacionales jurídicamente vinculantes que llevan a la práctica el principio 10 de la Declaración de Río sobre el Medio Ambiente y el Desarrollo. La Convención de Aarhus sobre acceso a la información, participación pública en la toma de decisiones y acceso a la justicia en asuntos ambientales es ampliamente considerada como un logro notable en el derecho 
internacional, puesto que otorga derechos esenciales para contribuir a la justicia ambiental. En este sentido, las partes en la Convención deben garantizar que la ciudadanía sea consultada e involucrada en las decisiones que afectan el medio ambiente, pero también deben garantizar que la ciudadanía pueda impugnar las decisiones que ya se han tomado. En efecto, la Convención de Aarhus establece que, en ciertos casos, las personas físicas y jurídicas, como las organizaciones no gubernamentales, puedan llevar un caso a un tribunal $\mathrm{u}$ otros organismos imparciales para permitir la revisión de actos u omisiones de organismos públicos o privados ${ }^{40}$.

Tanto la UE ${ }^{41}$ como sus 28 Estados miembros firmaron el Convenio y se comprometieron a implementarlo en sus sistemas legales ${ }^{42}$. En relación al acceso a la justicia, la UE ha aplicado el Convenio de Aarhus a través de la Directiva 2003/4/CE ${ }^{43}$, relativa al acceso del público a la información medioambiental como de la Directiva 2003/35/CE ${ }^{44}$, relativa a la participación del público en la elaboración de planes y programas relacionados con el medio ambiente, puesto que ambas contienen disposiciones sobre el acceso a la justicia. Si bien se adoptó una propuesta de Directiva sobre el acceso a la justicia en materia de medio ambiente de 2003, esta fue retirada en 2014 como parte de la revisión de la adecuación en la legislación de la UE llevada a cabo por la Comisión Europea ${ }^{45}$.

Con posterioridad se adoptó el Reglamento (CE) 1367/2006 ${ }^{46}$, que permite a las organizaciones no gubernamentales interponer recursos ante los tribunales europeos contra las decisiones de las instituciones y organismos en materia ambiental.

40 En particular, los arts. 9 (2) y (3) del Convenio de Aarhus. Cit. supra.

41 2005/370/CE: Decisión del Consejo de 17 de febrero de 2005 sobre la celebración, en nombre de la Comunidad Europea, del Convenio sobre el acceso a la información, la participación del público en la toma de decisiones y el acceso a la justicia en materia de medio ambiente (DO L 124, 17.5.2005, 1-3).

42 Véase la Decisión 2005/370/EC.

43 DO L 41, 14.2.2003, pp. 26-32.

44 DO L 156, 25.6.2003, pp. 17-25.

45 Véase el Programa REFIT. Consúltese el sitio web para más información: https:// ec.europa.eu/info/law/law-making-process/evaluating-and-improving-existing-laws/ refit-making-eu-law-simpler-and-less-costly_es (consulta el 1 de marzo de 2019). Reglamento (CE) 1367/2006 del Parlamento Europeo y del Consejo, de 6 de septiembre de 2006, relativo a la aplicación, a las instituciones y a los organismos comunitarios, de las disposiciones del Convenio de Aarhus sobre el acceso a la información, la participación del público en la toma de decisiones y el acceso a la justicia en materia de medio ambiente (DO L 264 de 25.9.2006, pp. 13-19). 
En 2008, la organización no gubernamental ClientEarth presentó un asunto ante el Comité de Cumplimiento del Convenio por insuficiente cumplimiento por parte de la UE de sus obligaciones en virtud del Convenio de Aarhus. El Comité, tras prolongados debates, presentó sus conclusiones a la UE el 17 de marzo de $2017^{47}$. En este sentido, el Comité de Cumplimiento del Convenio de Aarhus considera que la UE infringe las reglas del Convenio al no conceder un acceso suficiente a la justicia a las organizaciones de protección del medio ambiente y a la población general. Según el Comité, ni el Reglamento 1367/2006 de la UE, de 6 de septiembre de 2006, relativo a la aplicación, a las instituciones y a los organismos comunitarios, de las disposiciones del Convenio de Aarhus, ni la jurisprudencia del Tribunal de Justicia de la Unión Europea aplican o cumplen las obligaciones, en la medida que no otorgan una reparación administrativa o judicial suficiente, tal y como exige el Convenio en su art. 9 , párrs. 2 y $3^{48}$.

El Consejo de la UE, sin embargo, rechaza esta argumentación del Comité ${ }^{49}$ en la medida que como secunda la Comisión, las conclusiones del Comité no reconocen la función central de los tribunales nacionales en la aplicación del art. 9, apdo. 3, del Convenio de Aarhus ni el sistema de decisiones prejudiciales del Tribunal de Justicia de la Unión Europea como vía de recurso válida.

A continuación, en 2017, la Comisión adoptó un documento de orientación sobre el acceso a la justicia en materia medioambiental. En efecto, en la Comunicación de la Comisión relativa al acceso a la justicia en materia medioambiental, de 18 de agosto de $2017^{50}$, la Comisión aclara el modo en que los particulares y las asociaciones pueden impugnar, ante los órganos jurisdiccionales nacionales, las decisiones, actos y omisiones de las autoridades públicas en materia de derecho del medio ambiente de la UE. De este modo, la Comisión sostiene que la UE es una entidad legal única y que, dado que los

47 Asunto ACCC/C/2008/32, sobre el acceso a la justicia a nivel de la Unión. Disponible en: https:/www.unece.org/fileadmin/DAM/env/pp/compliance/C2008-32/ correspondence/toCommre2008-32.2008.12.24.pdf y también consultar la Decisión VI/8f relativa al cumplimiento por la Unión Europea de sus obligaciones en virtud del Convenio, disponible en: https://www.unece.org/fileadmin/DAM/env/pp/mop6/ Documents_aec/ECE.MP.PP.2017.25_DD_EU_advance_copy.pdf (ambas consultas el 1 de marzo de 2019).

Asunto ACCC/C/2008/32, ibid., apdo. 123.

49 Decisión del Consejo relativa a la posición que deberá adoptarse, en nombre de la Unión Europea, en el sexto periodo de sesiones de la Reunión de las Partes en el Convenio de Aarhus respecto al asunto ACCC/C/2008/32. Bruselas, 29.6.2017 $\operatorname{COM}(2017) 366$ final 2017/0151 (NLE).

DO C 275/1, de 18 de agosto de 2017. 
ciudadanos pueden impugnar las decisiones a través de sus tribunales nacionales, no es necesario otorgar acceso directo a nivel europeo, excluyendo así los litigios entre particulares en materia de medio ambiente y la revisión judicial de los actos de las instituciones de la Unión Europea. Por lo tanto, se deja la función de custodia de la Naturaleza en manos de la ciudadanía y asociaciones europeas. El mismo TJUE ha declarado que corresponde al juez nacional, a fin de garantizar la tutela judicial efectiva en los ámbitos cubiertos por el derecho ambiental de la Unión, interpretar su derecho nacional de manera conforme, en la medida de lo posible, a los objetivos del Convenio de Aarhus ${ }^{51}$.

En este sentido, el TJUE ha dictado diversas sentencias que aclaran los requisitos de la UE sobre el acceso a la justicia en asuntos de medio ambiente: sobre cómo deben abordar los órganos jurisdiccionales nacionales las alegaciones de que los planes sobre la calidad del aire de ámbito municipal no prevean medidas suficientemente eficaces para alcanzar los niveles de calidad del aire establecidos por la UE; sobre la función que pueden desempeñar los ciudadanos, principalmente las organizaciones no gubernamentales de protección del medio ambiente, para ayudar a garantizar el cumplimiento en los Estados miembros de las obligaciones establecidas por la UE relativas a la naturaleza; y sobre los criterios de evaluación que los órganos jurisdiccionales nacionales deben emplear para evitar que unos gastos procesales excesivamente elevados impidan a los ciudadanos y las asociaciones cumplir su función de apoyar la legislación medioambiental de la UE a nivel nacional.

Con posterioridad, el 15 y el 16 de noviembre de 2017, respectivamente, el Parlamento Europeo adoptó una resolución respecto al «Plan de acción en pro de la naturaleza, las personas y la economía», y otra sobre la revisión de la aplicación de la normativa medioambiental de la UE. En ambas, se instaba a la Comisión, entre otras cuestiones, a que presentara una nueva propuesta legislativa de revisión del Reglamento (CE) 1367/2006, a fin de tener en cuenta la recomendación del Comité de Cumplimiento del Convenio de Aarhus en relación con el asunto ACCC/C/2008/32.

Todas estas justificaciones no fueron admitidas por el Comité en la reunión de las Partes del Convenio, celebrada en Montenegro en septiembre de $2017^{52}$. El Comité de Cumplimiento llegó a la conclusión de que la UE había incumplido el Convenio, ya que ni el Reglamento pertinente ni la jurisprudencia del

51 Véase la Sentencia del Tribunal de Justicia (Gran Sala) de 8 de marzo de 2011, Lesoochranárske zoskupenie, C-240/09, EU:C:2011:125, apdo. 50.

52 Sixth session of the Meeting of the Parties to the Aarhus Convention, 11-13 September 2017, Budva, Montenegro. 
Tribunal de Justicia de la UE aplican ni cumplen las disposiciones del mismo sobre acceso a la justicia. En consecuencia, el Comité recomendaba que todas las instituciones competentes de la UE tomasen medidas para subsanar dichas deficiencias a fin de garantizar que la UE satisface plenamente sus obligaciones ${ }^{53}$.

$\mathrm{Al}$ respecto, el Consejo de la Unión Europea, haciendo uso de la potestad concedida por el art. 241 del TFUE ${ }^{54}$, adoptó una decisión el 11 de junio de 2018. La Decisión del Consejo entró en vigor el día de su publicación en el Diario Oficial de la Unión Europea, en concreto, el 19 de junio de $2018^{55}$. En esta decisión, el Consejo pide a la Comisión que finalice el estudio antes del 30 de septiembre de 2019 y que, en caso de que se considere adecuado modificar el Reglamento (CE) 1367/2006 a la vista de los resultados, elabore la propuesta pertinente para el 30 de septiembre de 2020, estableciendo las opciones para mejorar el acceso a la justicia de los ciudadanos y las ONG en asuntos medioambientales, incluida una posible revisión de la legislación pertinente de la UE. Asimismo, ante la necesidad de prepararse ante la próxima Reunión de las Partes del Convenio de Aarhus en 2021, la Comisión abrió una consulta pública sobre la implementación de la Convención de Aarhus en el área de acceso a la justicia en cuestiones ambientales ${ }^{56}$.

53 Findings and recommendations of the Compliance Committee with regard to Communication ACCC/C/2008/32 (Part II) concerning compliance by the European Union. Adopted by the Compliance Committee on 17 March 2017, ACCC/C/2008/32 (EU), Part II. Disponible en: https:/www.unece.org/fileadmin/DAM/ env/pp/compliance/C2008-32/Findings/C32_EU_Findings_as_adopted_advance_ unedited_version.pdf (consulta el 1 de marzo de 2019).

54 Este artículo establece que: «El Consejo, por mayoría simple, podrá pedir a la Comisión que proceda a efectuar todos los estudios que él considere oportunos para la consecución de los objetivos comunes y que le someta las propuestas pertinentes. Si la Comisión no presenta propuesta alguna, comunicará las razones al Consejo».

55 Véase la Decisión del Consejo por la que se solicita a la Comisión que presente un estudio sobre las opciones de la Unión para abordar las conclusiones del Comité de Cumplimiento del Convenio de Aarhus en el caso ACCC/C/2008/32 y, si corresponde, en vista de los resultados del estudio, una propuesta de Reglamento del Parlamento Europeo y del Consejo que modifica el Reglamento (CE) 1367/2006, de 11 de junio de 2018. Disponible en: http://data.consilium.europa.eu/doc/document/ ST-9422-2018-INIT/en/pdf (consulta el 1 de marzo de 2019).

56 La consulta pública se realizó del 20 de diciembre de 2018 hasta el 14 de marzo de 2019 para que el público interesado expresara su opinión al respecto. Pueden acceder a la consulta pública en: https://ec.europa.eu/info/law/better-regulation/initiatives/ ares-2018-2432060/public-consultation_en (consulta el 1 de marzo de 2019). 
No obstante estos avances, las ONG continúan luchando por la justicia ambiental e impulsando la implementación total de la Convención de Aarhus a nivel nacional y de la UE, mientras tanto, la UE enfrenta serias dudas sobre por qué trabajó tan duro para bloquear los derechos legales que imponen la responsabilidad democrática y ayudan a proteger el medio ambiente, y que ya deberían estar garantizados para todos los europeos. Quizá si se supera esta dificultad se pueda avanzar en el reconocimiento de los derechos de la Naturaleza, mediante el acceso a la justicia.

\section{EL MOVIMIENTO EUROPEO POR LOS DERECHOS DE LA NATURALEZA}

A raíz de todo lo expuesto, junto con el empoderamiento de la participación de la ciudadanía europea en la protección del medio ambiente, ha surgido un movimiento social europeo para la promoción y defensa de los derechos de la Naturaleza. Esto ha conllevado el planteamiento de una iniciativa ciudadana para la propuesta de una regulación jurídica de los derechos de la Naturaleza en la UE, junto con la propuesta celebración de un Tribunal Europeo sobre Derechos de la Naturaleza.

La iniciativa ciudadana europea (ICE) es un instrumento muy importante de la democracia participativa en la Unión, ya que permite participar a la ciudadanía de forma activa en la promoción de nuevas normas en el seno de la UE. Esta se articula con la firma de un millón de ciudadanos de la Unión que residan en al menos una cuarta parte de los Estados miembros, instando a la Comisión a presentar una propuesta de acto jurídico para aplicar los tratados de la Unión. Su regulación se incluye en el Reglamento (UE) 211/2011 ${ }^{57}$, que establece de forma pormenorizada los procedimientos y condiciones de la iniciativa ciudadana europea.

Haciendo uso de esta posibilidad participativa, el impulso de la sociedad civil para la protección de la Naturaleza en la UE se inició con la presentación, el 22 de enero de 2013, de la ICE denominada «Erradicar el ecocidio en Europa: una iniciativa ciudadana para otorgar derechos a la Tierra ${ }^{58}$, la cual no prosperó por no reunir el suficiente número de firmas. Siguiendo los mismos

57 Reglamento (UE) 211/2011 del Parlamento Europeo y del Consejo, de 16 de febrero de 2011, sobre la iniciativa ciudadana (DO L 65 de 11.3.2011, pp. 1-22).

58 El título en concreto era: «End Ecocide in Europe a Citizens' Initiative to give the Earth Rights». Consúltese https://web.archive.org/web/20121023115621/http://eradicatingecocide.com/eci/ y https://ipfs.io/ipfs/QmXoypizjW3WknFiJnKLwHCnL72vedxjQkDDP1mXWo6uco/wiki/European_Citizens'_Initiative.html (ambas consultas el 15 de abril de 2019). 
pasos que esta ICE, la organización Nature's Rights propone presentar una iniciativa ciudadana, entre 2019 y 2020, con el fin de proponer los derechos de la naturaleza en la agenda legislativa de la UE ${ }^{59}$. Así, en marzo de 2017, organizaron conjuntamente una conferencia con los eurodiputados Marco Affronte, Benedek Jávor y Pavel Poc en el Parlamento Europeo para presentar los derechos de la Naturaleza y una propuesta de un proyecto de directiva de la UE sobre esta cuestión ${ }^{60}$.

El borrador de la Directiva de la UE se preparó con el fin de lograr que los «derechos civiles» se extendieran al mundo natural y que se reconociera el derecho de la Naturaleza a existir, renovarse y mantener sus ciclos vitales. Con esta propuesta de norma innovadora se pretende reconocer el valor intrínseco de la Naturaleza, cambiando paradigmas de protección que ya no protegen y que fomentan la destrucción del medio natural.

Así, la propuesta de directiva comprende 22 artículos distribuidos en ocho partes: la primera parte se centra en las disposiciones generales de la directiva (arts. 1 a 3), incluye el objetivo de la directiva, el ámbito de aplicación y las definiciones. La segunda parte (arts. 4 a 6) se centra en los derechos de la Naturaleza propiamente dichos, en concreto, en los derechos sustantivos de la Naturaleza, derechos procedimentales de la Naturaleza y el deber de cuidado. La tercera parte (arts. 7 a 12) se refiere a la protección y garantía de los derechos de la Naturaleza, abordando los delitos contra la Naturaleza, la legitimación activa y los costes, la compensación y la restauración, el recurso del amicus curiae, el recurso judicial y el cumplimiento. La cuarta parte versa sobre «Gobernanza ecológica» (arts. 13 a 15). La parte quinta (art. 16) se refiere al «Ombusdman» como institución de defensoría de la Naturaleza. La parte sexta (arts. 17) aborda el seguimiento del impacto ambiental. La parte séptima (art. 18), el premio de los derechos de la Naturaleza. Y, finalmente, la parte octava (arts. 19 a 23), que incluye las disposiciones finales de la directiva.

Esta propuesta de directiva, que promueve la consideración de la $\mathrm{Na}-$ turaleza de objeto a sujeto, en la articulación de un nuevo marco normativo innovador que comprende: los derechos de la naturaleza, el derecho humano a un medio ambiente sano, los derechos de las generaciones futuras, el Defensor del Pueblo para la Naturaleza, un sistema judicial alternativo, la gobernanza ecológica, entre otras cuestiones transformadoras. Todos ellos elementos que

59 Para consultar el texto de esta propuesta véase http://www.natures-rights.org/ ECI-DraftDirective-Draft.pdf. También consúltese https://www.citizensforeurope. eu/organisation/rights-of-nature-europe (ambas consultas el 15 de abril 2019).

60 Véase el informe de la conferencia: http://files.harmonywithnatureun.org/uploads/ upload52.pdf (consulta el 15 de abril 2019). 
han sido fruto de las transformaciones inspiradoras provenientes de países, como Ecuador y Bolivia, que comparten, en diferente grado con la UE, el alto valor biológico y natural, pero también su vulnerabilidad y fragilidad. Por este motivo, esta propuesta de marco jurídico transformador incluye las diversas opciones, anteriormente analizadas, de materializar la personalidad jurídica de la Naturaleza en la UE. La primera opción, es decir, el reconocimiento y atribución de derechos a la Naturaleza, considerándola como una persona jurídica; la segunda, en la medida en que se articulan derechos procedimentales de protección y reparación; y, finalmente, la tercera mediante la propuesta de institucionalizar la figura de la custodia, a través de la propuesta de establecer una «Defensoría de la Naturaleza».

Con el ánimo de proseguir en esta línea de transformación, además de estas iniciativas mencionadas, la organización GARN (Global Alliance for the Rights of Nature) ha promovido el llamado «European Rights of Nature Hub», un hub regional de esta organización, que trabaja para promover los Derechos de la Naturaleza en Europa. Su actividad más relevante, en este sentido, ha sido la convocatoria del «Tribunal Europeo por los Derechos de la Naturaleza: En Defensa de los Ecosistemas Acuáticos», liderado por la sociedad civil, que se celebrará el 13 de junio de 2020 en Marsella (Francia), para enfrentar los casos severos de ecocidio y violaciones de los derechos de la Naturaleza que ocurren en Europa. En particular, la tarea de este tribunal de opinión será analizar los casos sometidos por la sociedad civil que más afectan al medio acuático, esto es, al océano, mar, lago, río, arroyo, glaciar, humedal, y/o aguas subterráneas, y valorar la pertinencia de reconocer su entidad en tanto que sujetos de derechos. En este sentido, la actividad de este tribunal será determinada por los casos, ya mencionados, de reconocimiento judicial de los derechos de los ríos.

En definitiva, todas estas propuestas presentadas son iniciativas que pretenden demostrar una tendencia transformadora de la protección ambiental a nivel de la Unión Europea, constatando a su vez la posibilidad del establecimiento de un marco inicial para el reconocimiento de los derechos de la naturaleza en la UE, introduciendo nuevos paradigmas normativos de protección del medio ambiente y de la Naturaleza, al igual que ha sucedido en otras partes del mundo.

\section{CONCLUSIONES}

La Naturaleza requiere de una protección sólida e integral en todos los países y estrategias comunes de actuación, si se quieren proteger a las personas y a todas las especies que interactúan y viven en sus diferentes ecosistemas, a 
la vez que se preservan y garantizan los derechos y libertades fundamentales. Para esto los aprendizajes, generados principalmente en el sur global son un ejemplo inspirador no solo de transformación del modo de proteger al medio ambiente, sino también de cambiar la relación entre los seres humanos y la Naturaleza.

Si bien la Unión Europea ha consagrado la protección del medio ambiente dentro de sus políticas y actividades, en particular con miras a promover el desarrollo sostenible, la aplicación de estas normas sigue siendo débil y nada en el derecho de la Unión o en el ordenamiento jurídico de ningún Estado miembro va tan lejos como para proteger los derechos de la Naturaleza. No obstante, se apuntan ciertos avances en este sentido.

El marco jurídico de los derechos de la Naturaleza y los pronunciamientos judiciales, que se están produciendo en este sentido en diferentes partes del mundo, constituyen un impulso inspirador importante para iniciar el camino hacia el establecimiento de un imperativo legal en la UE para su transformación sistémica, y lograr así su armonía con la Naturaleza. Para esto es importante establecer el primer paso: lograr la disociación del crecimiento económico de la destrucción del medio ambiente.

Otro paso necesario es implementar una concepción global de la Naturaleza, partiendo de la Red Natura 2000, evitando segregar los componentes interconectados de los ecosistemas y aproximarse a la visión biocéntrica de protección, es decir, a la Naturaleza per se, como sujeto de derechos, tal y como ha sucedido, por ejemplo, en Ecuador y Bolivia. A pesar de que el derecho ambiental de la UE contiene estándares de protección elevados, no se ha logrado contener la degradación del medio ambiente. En parte, porque no se tiene en cuenta la interconexión de todos los elementos naturales. Y, además, porque es un marco normativo que compite con otros intereses predominantes y que permite que las corporaciones y los ejecutivos se beneficien al ejercer su poder excesivo sobre los recursos, con frecuencia sin que se los responsabilice si sus acciones generan contaminación, degradación ambiental o injusticia social.

Si bien la propuesta de introducción de un enfoque basado en los derechos a través de la adopción de una nueva directiva podría ser atractiva, en última instancia, sería un método incapaz de implementar de manera integral los fundamentos que sustentan los derechos de la Naturaleza. En este sentido, lo más adecuado sería: o bien profundizar en las «Directivas de la Naturaleza» como marco jurídico potencialmente integrador de la protección ambiental en la UE o bien la adopción de un nuevo reglamento, que permita esta protección biocéntrica y uniformadora de los derechos de la Naturaleza en la UE.

Por otra parte, si bien la posibilidad de una reforma de los tratados de la UE a la luz de un enfoque más biocéntrico, basado en los derechos de la $\mathrm{Na}$ turaleza, parece ciertamente complejo a nivel de la UE, esta sería la vía más 
deseable, si se considera que el proceso de constitucionalización de los derechos de la Naturaleza en la UE en el derecho primario sería el máximo grado de protección a alcanzar en la actual situación de crisis ecológica. No obstante, la acción de subsidiariedad podría justificar una intervención de la UE, en virtud de su competencia compartida en la protección ambiental y sobre la base del insuficiente cumplimiento de las directivas ambientales, por parte de los Estados miembros y la consiguiente situación de degradación ambiental. Todos estos elementos justifican no solo la necesidad de una intervención subsidiaria de la UE, para el logro de todos sus objetivos de integración, sino también la urgencia de proteger el medio ambiente, propiciando una transformación del derecho de la UE y de los ordenamientos jurídicos de los Estados miembros, tal y como ya se está produciendo en otras partes del mundo. Con todo es importante constatar que, si se quieren garantizar los derechos humanos y libertades fundamentales, será necesario también propiciar nuevos paradigmas y planteamientos transformadores de la protección ambiental.

\section{Bibliografía}

Acosta, A. y Martínez, E. (eds.) (2009). Derechos de la Naturaleza - El futuro es ahora. Quito: Abya Yala.

Alblas, E. (2018). Conflicting goals and mixed rationales: A closer look at the objectives of EU environmental law in light of the Anthropocene. Review of European, Comparative and International Environmental Law, 27, 141-152. Disponible en: https://doi.org/10.1111/reel.12234.

Baker, S. (1997). The Evolution of EU Environmental Policy. En S. Baker, M. Kousis, D. Richardson y S. Young (eds.). The Politics of Sustainable Development (pp. 89-106). London: Routledge.

Baker, S. (2007). Sustainable development as symbolic commitment: Declaratory politics and the seductive appeal of ecological modernisation in the European Union. Environmental Politics, 16 (2), 297-317. Disponible en: https://doi. org/10.1080/09644010701211874.

Boff, L. (2008). El siglo de los derechos de la Madre Tierra. Koinonia, 8-5-2009. Disponible en: http://www.servicioskoinonia.org/boff/articulo.php?num=327.

Borrás, S. (2016). New Transitions from Human Rights to the Environment to the Rights of Nature. Transnational Environmental Law, 5 (1), 113-143. Disponible en: https://doi.org/10.1017/S204710251500028X.

Boyd, D. R. (2011). The Environmental Rights Revolution: A Global Study of Constitutions, Human Rights, and the Environment. Vancouver: UBC Press.

Boyd, D. R. (2017). The Rights of Nature: A Legal Revolution That Could Save the World. California: Ingram Publisher Services. 
Bozonnet, J. P. (2014). L'écocentrisme en Europe: une mise en récit de la nature, postindustrielle et post-religieuse. En P. Bréchon y F. Gonthier (eds.). Les valeurs des Européens, Évolution et clivages (pp. 89-104). Paris: Armand Colin.

Carwil, Bjork J. (2012). Bolivia’s new Mother Earth Law to sideline indigenous rights. Global Justice Ecology Project [blog], 24-8-2012. Disponible en: https://bit. ly/2PwkDEq.

Chapron, G., Epstein, Y. y López-Bao, J. V. (2019). A rights revolution for nature. Science, 363, 1392-1393. Disponible en: https://doi.org/10.1126/science. aav 5601.

Connelly, J. (2012). Environmental Policy in the European Union and the contested notion of sustainable development. Marmara Journal of European Studies, 20 (1), 199-217.

Cullinan, C. (2002). Wild Law: A Manifesto for Earth Justice. Cape Town: Siber Ink. Daly, E. (2012). Ecuadorian Exemplar: The First Ever Vindications of Constitutional Rights. Review of European Community and International Environmental Law, 21 (1), 63-66. Disponible en: https://doi.org/10.1111/j.1467-9388.2012.00744.x.

Davison, I. (2017). Whanganui River Given Status of a Person under Unique Treaty of Waitang Settlement. New Zealand Herald, 15-3-2017. Disponible en: https:// bit.ly/2TnL80h. [fecha de consulta: 10-10-2017].

Dunlap, R. E., Schmidt, L. y Guerra, J. (2011). Searching for an ecological worldview in Europe. Lisboa: Fundação Calouste Gulbenkian.

European Environment Agency (2018a). European waters: Assessment of status and pressures 2018. (EEA Report; 7/2018), 3-7-2018. Disponible en: https:/www. eea.europa.eu/publications/state-of-water/ [consulta: 1-3-2019].

European Environment Agency (2018b). Natural capital accounting in support of policymaking in Europe. A review based on EEA ecosystem accounting work (EEA Report; 26/2018). Disponible en: https://bit.ly/2TfXRls [consulta: 1-3-2019].

European Commission (2011). Our life insurance, our natural capital: an EU biodiversity strategy to 2020. Bruselas.

European Commission (2019). Report from the Commission 2018 - Annual report on monitoring the application of EU law. Disponible en: https://bit. ly/32ua0Hy. [fconsulta: 10-10-2019].

Fish, L. (2013). Homogenizing Community, Homogenizing Nature: An Analysis of Conflicting Rights in the Rights of Nature Debate. Stanford Undergraduate Research Journal, 6, 10.

García Ureta, A. (2005). Aspectos sobre el acceso a la justicia en el Convenio de Aarhus y su incidencia en el Derecho comunitario. Ingurugiroa eta Zuzenbidea, 3, 132 .

Gudynas, E. (2009). El mandato ecológico - Derechos de la Naturaleza y políticas ambientales en la nueva Constitución. Quito: Abya-Yala.

Gudynas, E. (2010). La senda biocéntrica: valores intrínsecos, derechos de la naturaleza y justicia ecológica. Tabula Rasa, 13. Disponible en: https://doi. org/10.25058/20112742.404. 
Gudynas, E. (2011). Los Derechos de la Naturaleza - Respuestas y aportes desde la ecología politica. Quito: Abya-Yala.

Hovden, K. (2018). The Best Is Not Good Enough: Ecological (Il) literacy and the Rights of Nature in the European Union. Journal for European Environmental and Planning Law, 15, 3-4. Disponible en: https://doi.org/10.1163/1876010401503004.

Hunka, A. D., De Groot, W. T. y Biela, A. (2009). Visions of Nature in Eastern Europe: A Polish Example. Environmental Values, 18 (4), 429-452. Disponible en: https://doi.org/10.3197/096327109X12532653285777.

İzci, R. (2005). The Impact of the European Union on Environmental Policy. En F. Adaman y M. Arsel (eds). Environmentalism in Turkey: Between Democracy and Development? (pp. 101-114). Farnham: Ashgate.

Knauß, S. (2018). Conceptualizing Human Stewardship in the Anthropocene: The Rights of Nature in Ecuador, New Zealand and India. Journal of Agricultural and Environmental Ethics, 31 (6), 703-722. Disponible en: https://doi. org/10.1007/s10806-018-9731-x.

Macías Gómez, L. F. (2010). El constitucionalismo ambiental en la nueva Constitución de Ecuador. Un reto a la tradición constitucional. Iuris Dictio, 12 (14), 151-168. Disponible en: https://doi.org/10.18272/iu.v12i14.704.

Martínez, E. y Acosta, A. (2014). La Naturaleza entre la cultura, la biología y el derecho. La Naturaleza con derechos. Quito: Instituto de Estudios Ecologistas del Tercer Mundo.

Martínez, E. y Acosta, A. (2017). Los Derechos de la Naturaleza como puerta de entrada a otro mundo posible. Revista Direito e Práxis, 8 (4), 2927-2961. Disponible en: https://doi.org/10.1590/2179-8966/2017/31220.

O’Donnell, E. L. y Talbot-Jones, J. (2018). Creating legal rights for rivers: lessons from Australia, New Zealand, and India. Ecology and Society, 23 (1), 7. Disponible en: https://doi.org/10.5751/ES-09854-230107.

Pagden, A. (2015). Human Rights, Natural Rights, and Europe's Imperial Legacy. The Burdens of Empire: 1539 to the Present. Cambridge: Cambridge University Press.

Roy, E.A. (2017). New Zealand River Granted Same Legal Rights as Human Being. The Guardian, 16-3-2017. Disponible en: https://bit.ly/3a1BO8W. [consulta: 10-10-2018].

Ruiz de Apodaca Espinosa, A. (2018). El acceso a la justicia ambiental a nivel comunitario y en España veinte años después del Convenio de Aarhus. Revista Catalana de Dret Ambiental, 9 (1), 1-53. Disponible en: https://doi.org/10.17345/2410.

Schoukens, H. (2018). Granting Legal Personhood to Nature in the European Union: Contemplating a Legal (R)evolution to Avoid an Ecological Collapse (Part 1). Journal for European Environmental and Planning Law, 15 (3-4), 309-332. Disponible en: https://doi.org/10.1163/18760104-01503005.

Shelton, D. (2015). Nature as a legal person. VertigO. La Revue Électronique en Sciences de l'Environnement. Disponible en: https://bit.ly/2TxdrJN. [consulta: 1-3-2019]. Disponible en: https://doi.org/10.4000/vertigo.16188. 
Stone, C. (1972). Should Trees Have Standing? Toward Legal Rights for Natural Objects. Southern California Law Review, 45, 450.

Stutzin, G. (1984). Un imperativo ecológico: reconocer los derechos de la Naturaleza. Disponible en: https://bit.ly/2wTh3ht. [consulta: 1-1-2019].

TNS Political and Social (2015). Attitudes of European towards biodiversity. Flash Eurobarometer n. 436. European Commission. Bruselas.

Tribunal de Cuentas Europeo (2018). Bienestar animal en la UE: reducir la diferencia entre unos objetivos ambiciosos y su aplicación práctica. (Informe especial, 31). Disponible en: https://bit.ly/2T1nLdU. [consulta: 1-3-2019].

Zweers, W. (2000). Participating with Nature: Outline for an Ecologization of Our World View. Utrecht: International Books. 